DEVELOPMENT OF A FIELD WORTHY SENSOR SYSTEM TO MONITOH GASEOUS NITROGEN TRANSFER FROM AGRICULTURAL CROPLAND Phase I

Final Report

November 1992

Work Performed Under Contract No. FC02-89ID12905

For

U.S. Department of Energy

Office of Industrial Technologies

Washington, D.C.

By

Georgia Tech Research Institute

Atlanta, Georgia 


\section{DISCLAIMER}

This report was prepared as an account of work sponsored by an agency of the United States (iovernment. Neither the United States Covernment nor any agency thereof, nor any of their employecs. mokes any warranty. express or implied, or assumes any legal hability or responsibility for the accuracy, completenes, or usefulness of any information, apparatus, profuct, or process disclosed, or represents that its use would not infringe privately owned rights. Reference herein to any specific commercial product, process, or service by trade name. trademark, manufacturer, or otherwise does not necessarily constitute or imply its endorsement, recommendation, or favoring by the United States Government or any agency thereof. The view's and opinions of authors ex pressed herein do not necessarily state or reflect those of the United States Government or any agency ihereof.

This report has been reproduced directly from the best available copy.

Available to DOE and DO contrac ors from the Office of Scientific and Technical Information. P.C. Box 62. Oak Ridge, TN 37831; prices available fron $16151576-8401$.

Available to the public from the National Technical Information Service, U. S. Department of Commerce, 5285 Port Royal Rd., Springfield, VA 22161. 
DOE/ID/12905--T3

DE93 003284

\title{
DEVELOPMENT OF A FIELD WORTHY SENSOR SYSTEM \\ TO MONITOR GASEOUS NITROGEN TRANSFER \\ FROM AGRICULTURAL CROPLAND
}

\section{Phase I}

Final Report

November 1992

Work Performed Under Contract No. DE-FC07-89ID12905

\author{
Prepared for the \\ U.S. Department of Energy \\ Under DOE Idaho Field Office \\ Sponsored by the Office of the Assistant Secretary \\ for Conservation and Renewable Energy \\ Office of Industrial Technologies \\ Washington, D.C. \\ Prepared by \\ Georgia Tech Research Institute
}




\section{EXECUTIVE SUMMARY}

Nitrogen (N) fertilizer accounts for 25 to $33 \%$ of the energy requirements in modern crop agriculture in the world today (Lemon and Van Houtte 1980). Energy input for the manufacture of these $N$ fertilizers is in the range of $460 \times 10^{12}$ Btu per year (Davis and Boudin 1977; Boswell et al. 1985). Unfortunately, for some $\mathrm{N}$ sources up to $70 \%$ of this energy in the form of $\mathrm{NH}_{3}$ can be lost through improper application techniques and poor $\mathbf{N}$ management strategies.

Because it is a gas at atmospheric pressure and temperatures greater than $13^{\circ} \mathrm{F}\left(-33.5^{\circ} \mathrm{C}\right)$, anhydrous $\mathrm{NH}_{3}$ may be lost to the atmosphere during and after placement due to soil conditions and the depth and spacing of placement. Inadequate soil conditions, improper injector settings, and erroneous injection rates enhance this loss. Moreover, urea and urea-ammonium nitrate solution (UAN) are becoming the principal $\mathrm{N}$ sources for broadcast as well as placement application in agriculture. These sources are often not incorporated into the soil and may be less efficient sources of $\mathrm{N}$ fertilizers because of $\mathrm{N}$ loss via gaseous $\mathrm{NH}_{3}$. Measurement of this volatile $\mathrm{N}$ is difficult, especially under field conditions. However, a precise and convenient method of measuring gaseous $\mathrm{NH}_{3}$ near and above the soil surface is prerequisite to the development and evaluation of alternative fertilizer management strategies and application techniques which can reduce the potential for significant loss.

Recent advances in integrated-optic (IO) based sensing offers the potential of measuring low levels of $\mathrm{NH}_{3}$ loss from a cropping system in the range of $100 \mathrm{ppb}$. The integrated design of an 10 system allows for a more durable device that can be mass produced at low cost. Utilization of this sensor technology may be a feasible approach but must be tested under practical conditions to assess accuracy and reliability.

Under Phase I of this project, two intergrated-optic (IO) devices were designed and tested: an absorption device using an oxazine dye as a waveguide coating and an interferometric device using an anilinium salt as a waveguide coating. The following results have been determined:

- An absorption device using oxazine 720 perchlorate as a waveguide coating was found to have a lower sensitivity level of $10 \mathrm{ppm}$ and exhibited a very rapid response (seconds) to exposure to $\mathrm{NH}_{3}$ in air concentrations. The device also exhibited a high level of sensitivity to changing humidity concentrations.

- An interferometric device usirg dodecylanilinium chloride as a waveguide coating was found to have a lower sensitivity level of $10 \mathrm{ppm}$ and had a rapid response (seconds); however, the correlation between sensor response (phase shift) and $\mathrm{NH}_{3}$ concentration was more linear than the absorption device. The interferometric device also exhibited a sensitivity to changing humidity levels, however, with a less pronounced effect than that exhibited by the absorption device.

- More emphasis on sensor design and fabrication should raise the sensitivity of a sensor at least an order of magnitude and reduce or null the effects of varying humidity in air. 
- With the apparent capacity of either sensor to measure in the low ppm range $\mathrm{NH}_{3}$ concentrations and the strong potential of increased sensitivity with improved fabrication and chemical deposition techniques, sensor applications could vary from a tractor mounted (mobil) device to an in-situ field device.

\section{BACKGROUND}

\section{Agricultural Nitrogen Applications}

The application of $\mathrm{N}$ fertilizer to a cropping system accounts for up to one-third of the overall energy requirement of that system. Nitrogen application will vary with soil type, weather conditions, type of crop, and crop cycle. The form in which the $\mathbf{N}$ is applied varies from broadcast granular fertilizers such as urea and ammonium nitrate to sprayed low-pressure or non-pressure liquids to injected anhydrous $\mathrm{NH}_{3}$.

Anhydrous $\mathrm{NH}_{3}$, a high-pressure liquid, contains $82 \% \mathrm{~N}$ and is considered the least expensive and most widely used source of $\mathbf{N}$ in the United States. Of the fertilizer $\mathbf{N}$ used in the United States, $90 \%$ is in the form of $\mathrm{NH}_{3}$ or $\mathrm{NH}_{4}{ }^{+}$-producing compounds and approximately $65 \%$ of this is anhydrous (Englestad et al. 1985). A water-soluble gas at normal temperatures and atmospheric pressure, anhydrous $\mathrm{NH}_{3}$ must be stored and haridled as a liquid under pressure in special cylinders. Anhydrous $\mathrm{NH}_{3}$ has a boiling point of $13^{\circ} \mathrm{F}$ and can be liquified under slight pressure. The gage vapor pressure of liquified $\mathrm{NH}_{3}$ is approximately $125 \mathrm{psi}$ at $75^{\circ} \mathrm{F}$ and $250 \mathrm{psi}$ at $115^{\circ} \mathrm{F}\left(860 \mathrm{kPa}\right.$ at $24^{\circ} \mathrm{C}$ and $1720 \mathrm{kPa}$ at $\left.46^{\circ} \mathrm{C}\right)$ (Kepner et al. 1978). As illustrated in Figure 1, anhydrous $\mathrm{NH}_{3}$ is injected as a liquid by a pump into a furrow opened by a knife/injector device. Since the liquid immediately vaporizes as it leaves the injector, a press wheel or coulter is sometimes used to close the furrow behind the injector to reduce losses.

Aqua $\mathrm{NH}_{3}$ is a solution of $\mathrm{NH}_{3}$ in water with the fertilizer grade containing 1 part $\mathrm{NH}_{3}$ to 3 parts water $(20.5 \% \mathrm{~N})$. A saturated solution of $\mathrm{NH}_{4} \mathrm{OH}$ contains $40 \% \mathrm{~N}$. Both are considered low-pressure liquids that must be kept in pressurized containers that seldom exceed $25 \mathrm{psi}(170 \mathrm{kPa})$. These low pressure solutions are applied using custom applicator spray rigs (Figure 2) or smaller rigs on tractors. Both high- and low-pressure liquids are applied through sprinkler and furrow irrigation although it is generally not recommended due to the high volatilization losses (up to $60 \%$ for sprinkler irrigation and $84 \%$ for furrow, Englestad et al. 1985).

Granular $\mathbf{N}$ fertilizers are typically broadcast over the soil surface which may or may not be turned to cover the fertilizer. Other methods include banding the fertilizer away from the seed in a subsurface application. In either case, bulk fertilizer applicators similar to the lowpressure liquid applicator in Figure 2 are used to cover large acreage, typically on a contract basis. Tractor mounted spreader units are used on smaller operations.

\section{Nitrogen Losses}

The process by which $\mathrm{N}$ is lost from the soil surface after application as $\mathrm{NH}_{3}$ gas is termed $\mathrm{NH}_{3}$ volatilization. Both low and high- pressure liquids are susceptible to vaporization losses if they are not injected deep enough or properly covered or are over-applied. Anhydrous 
$\mathrm{NH}_{3}$, aqua $\mathrm{NH}_{3}$, and other low-pressure liquids should be released in narrow furrows at a depth of at least $4-6$ in $(10-15 \mathrm{~cm})$ and covered immediately to prevent the escape of $\mathrm{NH}_{3}$ (Kepner et al. 1978). A loose, friable soil with adequate moisture and free of crop residue is important for good sealing and for adsorption of $\mathrm{NH}_{3}$ on the soil particles. Since $\mathrm{NH}_{3}$ escaping from the soil after injection is spread vertically by turbulent diffusion and convected horizontally by the wind (Denmead et al. 1977), both windspeed and temperature will have an effect on the rate of loss. Most importantly, anhydrous $\mathrm{NH}_{3}$ volatilization losses are a function of application rate: if tractor speed or the rate of flow exceed the capability of the soil to retain it or the plant to use it, losses will increase.

As illustrated in Figure 3, $\mathrm{NH}_{3}$ volatilization may occur when ammoniacal or ammoniumforming fertilizer is applied to the soil surface or when crop residues of high $\mathbf{N}$ content are returned to the soil surface without incorporation. These are common management practices with sod crops and in no-tillage crop production.

Losses under field conditions generally are in the range of 10 to $50 \%$ of the applied $\mathrm{N}$, but they can be as great as 60 to $70 \%$. Since $N$ fertilizer application rates are usually in the range of 90 to $270 \mathrm{lb}$ acre ${ }^{-1}$ (100 to $300 \mathrm{~kg} \mathrm{ha}^{-1}$ ), $\mathbf{N H}_{3}$ volatilization represents a substantial $\mathrm{N}$ loss from the soil-plant system. Nitrogen losses through $\mathrm{NH}_{3}$ volatilization will vary with crop, soil conditions, and weather. Harper et al. (1983) reported $\mathrm{NH}_{3}$ concentrations of up to $2.5 \mathrm{ppm}$ $\left(1800 \mu \mathrm{g} \mathrm{m}^{-3}\right)$ after urea application on a grazed sub-tropical cattle pasture system representing annual $\mathrm{NH}_{3}$ losses of 24 percent of the applied urea $\mathrm{N}$. Similarly, $\mathrm{NH}_{3}$ losses of approximately $21 \%$ of the $\mathrm{N}$ fertilizer applied were detected from no-till wheat fertilized with ammonium nitrate (Harper et al. 1987). Hargrove et al. (1987) noted $\mathrm{NH}_{3}-\mathrm{N}$ losses of up to $72 \%$ on a mulched soil surface treated with urea $\mathrm{N}$.

Factors in the soil that influence the volatilization of $\mathrm{NH}_{3}$ include soil $\mathrm{pH}$, soil hydrogen ion $\left(\mathrm{H}^{+}\right)$buffering capacity and cation-exchange capacity, and urease activity. When ammonium salts or ammonium-forming fertilizers are added to soil, ammonium ions $\left(\mathrm{NH}_{4}{ }^{+}\right)$and $\mathrm{NH}_{3}$ are in equilibrium in the soil solution according to reaction (1). The activity of $\mathrm{H}^{+}$ions,

$$
N H_{4}^{+}-N_{3}+H^{+}
$$

or the $\mathrm{pH}$, largely determines the ratio of $\mathrm{NH}_{3}$ to $\mathrm{NH}_{4}{ }^{+}$. At $\mathrm{pH} 9.3$, the ratio is about 1:1. At $\mathrm{pH}$ values greater that 7.0 , significant $\mathrm{NH}_{3}$ volatilization can occur, but as long as $\mathrm{pH}$ remains less that 7.0, $\mathrm{NH}_{3}$ losses are generally insignificant.

Soil $\mathrm{pH}$ is subject to rapid change following fertilizer applications, resulting from microbial activity and other chemical factors. A soil property more important than initial soil $\mathrm{pH}$ in determining $\mathrm{NH}_{3}$ loss potential is the capacity of the soil to resist changes in $\mathrm{pH}$, or its $\mathrm{H}^{+}$buffering capacity. The amount of buffering between the initial soil $\mathrm{pH}$ and a $\mathrm{pH}$ of about 7.5 is more directly related to the expected $\mathrm{NH}_{3}$ loss than to the initial soil pH. Soil cationexchange capacity is also important because it allows $\mathrm{NH}_{4}^{+}$ions to be removed from soil solution, thereby reducing the total amount of $\mathrm{NH}_{3}$ subject to volatilization. Soils with high $\mathrm{pH}$ but also a high cation-exchange capacity actually lose only a small amount of $\mathbf{N H}_{\mathbf{3}}$. 
Urease is the enzyme which converts urea to $\mathrm{NH}_{3}$ and $\mathrm{CO}_{2}$. It is produced by both higher plants and microorganisms and occurs in soil both in living organisms and as free enzyme external to living organisms. Abundant urease and rapid urea hydrolysis results in an increased potential for $\mathrm{NH}_{3}$ loss, since this generally results in increased $\mathrm{pH}$ and greatly increased concentrations of $\mathrm{NH}_{4}{ }^{+}$ions. The following factors have been found to influence urease activity: (1) Soil organic matter content: as organic carbon increases, urease activity also increases. (2) Soil pH: the optimum soil $\mathrm{pH}$ for urease activity is between 7 and 9 , with reduced activity at very acid $(<5.0)$ and very alkaline $(>9.0) \mathrm{pH}$ values. (3) Soil temperature: generally, urease activity increases as temperature increases over the range of 50 to $149^{\circ} \mathrm{F}(10$ to $65^{\circ} \mathrm{C}$ ) and decreases above $149^{\circ} \mathrm{F}\left(65^{\circ} \mathrm{C}\right)$. (4) Soil water content: urease activity generally increases with increasing moisture content up to field capacity; at soil water potentials less than $15 \mathrm{~atm}\left(-5 \times 10^{5}\right.$ pascal), urease activity is considerably reduced; a negative effect at moisture contents above field capacity has also been reported. (5) Urea concentration: an increase in urease hydrolysis rates usually accompau.ies high rates of urea application.

Although urease activity varies considerably from soil to soil and under various climatic regimes, urease concentration seldom limits $\mathrm{NH}_{3}$ volatilization under field conditions. Generally, environmental factors are more important than urease concentration in determining total $\mathrm{NH}_{3}$ losses under field conditions. Environmental influences on the loss of $\mathrm{NH}_{3}$ include temperature, soil water content, and air exchange. Under controlled conditions, $\mathrm{NH}_{3}$ losses increase with increasing temperature over the range of 41 to $113^{\circ} \mathrm{F}\left(5\right.$ to $\left.45^{\circ} \mathrm{C}\right)$. This is due to temperature effects on chemical and biological reactions, especially on urease activity. However, the influence of temperature on $\mathrm{NH}_{3}$ loss under field conditions is quite complex and is also closely related to soil water content.

The influence of soil water content has been most difficult for scientists to quantify in a consistent manner under dynamic field conditions, especially where the soil water content fluctuates widely on a diurnal basis because of the combined effects of dew formation and evaporation. However, from research conducted under field conditions, several relationships have emerged. (1) For maximum $\mathrm{NH}_{3}$ loss rates, the soil water content must be at or near field capacity at the time of fertilizer application. If the soil is dry, dissolution of dry fertilizer materials is very slow, and thus the biological and chemical reactions necessary for $\mathbf{N H}_{3}$ volatilization are very slow or do not occur at all. (2) On a diurnal basis, maximum $\mathbf{N H}_{3}$ loss rates occur when the soil surface is drying. As the soil dries, the concentration of $\mathrm{NH}_{4}^{+}$and $\mathrm{NH}_{3}$ in the soil solution increases, resulting in $\mathrm{NH}_{3}$ being lost to the atmosphere to maintain equilibrium. (3) If the soil surface dries but is not rewetted by dew or light rainfall, $\mathbf{N H}_{3}$ loss is reduced because of insufficient moisture for the necessary biological and chemical reactions. (4) If rainfall is sufficient to move the $\mathrm{N}$ source into the soil profile, $\mathrm{NH}_{3}$ volatilization ceases. The exact amount of rainfall necessary to ensure no $\mathrm{NH}_{3}$ loss depends on soil type, but for most soil types is 0.4 to 0.8 in $(1$ to $2 \mathrm{~cm}$ ).

Considering all of these relationships, the influence of soil water content can be summarized as follows: On a diurnal basis, high $\mathrm{NH}_{3}$ loss rates are generally associated with periods of rapid soil drying as long as the soil is not too dry initially, but high total $\mathrm{NH}_{3}$ losses are associated with an initially moist surface soil followed by several days with no or small rainfall events. 
Air exchange at the soil surface is also an important factor that influences the $\mathrm{NH}_{4}^{+} / \mathrm{NH}_{3}$ equilibrium and has been overlooked by many researchers. In laboratory systems, it was found that relative $\mathrm{NH}_{3}$ losses were maximum when the air exchange rate was at least 10 chamber volumes per minute (the air above the soil was completely replaced ten times per minute). Field measurement techniques that utilize enclosures generally do not allow normal air exchange and thus do not mimic field conditions effectively.

\section{Current Techniques for Monitoring}

The four techniques for field measurement of $\mathrm{NH}_{3}$ volatilization are forced-draft techniques (Hargrove et al. 1987); micrometeorological techniques (Denmead et al. 1977 and Harper et al. 1987); recovery of ${ }^{15} \mathrm{~N}$, a stable, naturally occurring $\mathbf{N}$ isotope (Hargrove et al. 1987); and plant response. The forced-draft and micrometeorological techniques involve direct measurement of volatilized $\mathrm{NH}_{3}$, while the ${ }^{15} \mathrm{~N}$ recovery and plant response methods are indirect methods.

The two direct methods utilize wet chemistry analyses to provide $\mathrm{NH}_{3}$ concentrations. These techniques are tedious and time consuming and cannot provide "real-time" monitoring of $\mathrm{NH}_{3}$ losses from a crop. Furthermore, the techniques also do not avail themselves as a practical, farm-use tool for the management of $\mathrm{N}$. Therefore, the development of improved $\mathrm{N}$ management and application strategies is hindered by the lack of responsive monitoring techniques.

\section{Electronic Sensor Technologies}

Technologies that are commercially available for continuously monitoring atmospheric $\mathrm{NH}_{3}$ levels include metal oxide semiconductor (MOS), electrochemical, and photoionization. MOS based sensors work on the principal of ionoadsorbtion whereby oxidation reduction type reactors at the sensor surface has the result of altering the gross conductive properties of the material (Clifford and Tuma 1982). The effect can be measured as a change in resistance. While they have been used for monitoring $\mathrm{NH}_{3}$ levels below $100 \mathrm{ppm}\left(70 \mathrm{mg} \mathrm{m}^{-3}\right)$, MOS sensors are temperature sensitive and are not very species specific. These sensors can be mass produced at a cost of approximately $\$ 500$; however, performance at levels below $10 \mathrm{ppm}\left(7 \mathrm{mg} \mathrm{m}^{-3}\right)$ is very suspect.

Electrochemical $\mathrm{NH}_{3}$ sensors, while more species specific through the use of special electrolytes and gas-permeable membranes, are subject to interference from temperature and humidity changes (Ross and Daley 1986; Ross 1987). Moreover, sensor response and sensitivity is not sufficient to monitor $\mathrm{NH}_{3}$ levels below $1 \mathrm{ppm}\left(0.7 \mathrm{mg} \mathrm{m} \mathrm{m}^{-3}\right)$. These sensors, in their current form, are not in the form for mass production and currently cost in the range of $\$ 1,200$ to $\$ 2,500$.

Photoionization based sensors involve the process of exposing trace molecules to an ultraviolet light source which are in turn collected and measured for a proportional concentration reading. Interference from atmospheric UV could be a problem. These sensors typically cost over $\$ 10,000$.

\section{Integrated-Optic Chemical Sensors}

Optical sensors have recently been demonstrated as capable of measuring soil organic matter levels rapidly and accurately. In this case, the sensor transponder was mounted to a 
tractor tool bar and inserted into the soil as the tractor moved through a field (Gaultney et al. 1988).

Integrated-optics (IO) is a relatively new optical waveguide technology developed in the early 1970 s with much of the early emphasis devoted to communication aspects and signal processing applications (Verber 1984 and Alferness 1984). It relies on planar waveguide structures rather than the more familiar cylindrical optical fiber configuration. The planar waveguide consists of a thin layer of slightly higher refractive index material formed or deposited on the surface of a planar substrate. Direct access to the waveguide surface provides distinct advantages as thin film elements may be incorporated into or on the waveguide surface to create two dimensional optical systems capable of performing all the functions of standard bulk optical systems. More importantly, access to the waveguide surface provides the basis for innovative sensor configurations relying on the interaction of a guided optical beam with a cover or surrounding medium.

\section{PROJECT GOALS AND OBJECTIVES}

The goal of this project is to develop a field-worthy sensor system to monitor gaseous $\mathrm{NH}_{3}-\mathrm{N}$ transfer from agricultural cropland. Monitoring these losses would promote several avenues of $\mathrm{NH}_{3}$ conservation including minimizing application losses due to poor equipment settings and improving application strategies through a better understanding of the relationship between fertilizer application and $\mathrm{NH}_{3}$ volatilization. In both cases, an improvement in application efficiency and $\mathrm{N}$ utilization efficiency would reduce the amount of fertilizer applied resulting in significant cost and energy savings. Also, these goals could contribute to improved $\mathrm{N}$ management as related to environmental pollution concerns.

The objectives of this study are divided into three separate phases:

\section{Phase I: Laboratory and Bench-Scale Research}

- Design and test an integrated-optic sensor for monitoring low levels of $\mathrm{NH}_{3}$ under simulated field conditions.

- Determine the relationship between sensor output and simulator $\mathrm{N}$ losses.

- Develop alternative sensor uses, i.e. $\mathrm{N}_{2} \mathrm{O}$ or other gaseous $\mathrm{N}$ forms, dependent on adaptability for $\mathrm{NH}_{3}$ monitoring.

\section{Phase II: Prototype Development}

- Develop the IO sensor system to a level suitable for field testing.

- Improve bonding between chemically sensitive cover medium and waveguide.

- Incorporate optical components into single integrated device. 
Phase III: Field Research

- Conduct field tests of the sensor system to determine the accuracy
and reliability of sensor system under field conditions.
Use the sensor system to evaluate alternative management
strategies for improving fertilizer $\mathrm{N}$ use efficiency.
Evaluate the sensor for potential use by commercial anhydrous
$\mathrm{NH}_{3}$ applicators to monitor $\mathrm{NH}_{3}$ losses during application.

\section{TECHNICAL DISCUSSION}

Integrated Optic Waveguide Sensor

The chemical sensor configuration utilized in this program relied on a planar optical waveguide structure operating in an interferometric and an absorption mode. The integrated optic (IO) interferometric configuration functions by sensing small refractive index changes resulting from the interaction of the species to be detected with a thin chemically selective film attached to the waveguide surface. The inherent thermal and mechanical stability of the integrated design results in high detection sensitivity $\left(\Delta n=\leq 10^{-6}\right)$ corresponding to concentration levels in the ppm to ppb range. The absorption mode relies on the absorption of optical energy from the guided wave by a thin chemically selective film applied to the waveguide surface. Because the operation of the absorption device is relatively straight forward, the following discussions will concentrate on the interferometric based sensor.

The IO waveguide interferometric configuration most applicable to chemical sensing is the Mach-Zehnder arrangement. Both single mode and multimode Mach-Zehnder waveguide versions (Hartman 1990) are available with the latter best suited for real applications due to ease of input/output coupling and manufacturing. The single mode interferometer is essentially a laboratory device due to critical alignment issues. Technical discussions will emphasize the single mode Mäch-Zehnder configuration due to relative ease of understanding the basic IO interferometer operation. In practice, however, both the multimode and single mode interferometer operating principle:s are identical.

An IO Mach-Zehnder interferqmeter in a chemical sensor configuration is shown in Figure 4. One arm of the interferometer (signal arm) is coated with a thin film designed to be reactive with the desired species to be detected. The remaining arm is uncoated or alternatively coated with a protective layer or other materials that might be used for purposes of nulling interferant signals. The evanescent field of the guided wave in the signal arm (Figure 5) penetrates the waveguide/surface film interface, forming an exponentially decaying field in the surface film. As a result, refractive index variations within the surface film alters the phase of the guided beam through the evanescent interaction. The resulting phase shift is easiiy detected and monitored by interfering the signal arm guided wave with the reference signal guided wave and observing the fringe shift. In the case of the absorption device, guided wave energy is lost within the thin surface film due to absorption. 


\section{Analysis and Modeling}

For analysis of the interferometric configuration, a dispersion relationship can be developed relating IO waveguide parameters $n_{f}$ (film index), $n_{c}$ (cover film index), $n_{1}$ (substrate index) and W (waveguide film thickness) (Tien 1971; Kogelnik and Weber 1974). A convenient model for describing the interaction is based on the zig-zag ray model for the reflection of a optical ray between the two waveguide surfaces. The dispersion relationship can also be derived from an electromagnetic boundary value problem where a guided wave is confined by two dielectric boundaries. For ease of understanding and because both approaches yield the same result, only the ray model will be considered.

The dispersion relationship is defined by the "transverse resonance condition" which requires the sum of all phase shifts perpendicular to the direction of propagation in the waveguide to be a multiple of $2 \pi(\mathrm{m} 2 \pi$ where $\mathrm{m}=0,1,2, \ldots)$ for one zig-zag period as shown in Figure 5 (Kogelnik and Weber 1974). Thus the total phase shift associated with the transverse motion between the two boundaries must be an integer multiple of $2 \pi$ for each full cycle. For one transverse passage through the waveguide, a phase shift of $\mathrm{kn}_{\mathrm{f}} \mathrm{W} \cos \theta$ occurs. One full period however requires two transverse passages. Additionally, phase shifts of $-2 \theta_{c}$ and $-2 \theta$, occur due to total internal reflection at the cover and substrate boundaries of the waveguide (Hartman 1990). Thus the transverse resonance condition results in the following relationship for TE modes:

$$
\begin{aligned}
& 2 k n_{f} W \cos \theta-2 \theta_{c}-2 \theta_{s}-m(2 \pi) \\
& \text { where } \theta_{c}-\tan ^{-1}\left[\frac{\left(n_{f}^{2} \sin ^{2} \theta-n_{c}^{2}\right)^{1 / 2}}{n_{f} \cos \theta}\right] \\
& \text { and } \quad \theta_{s}-\tan ^{-1}\left[\frac{\left(n_{f}^{2} \sin ^{2} \theta-n_{s}^{2}\right)^{4 /}}{n_{f} \cos \theta}\right]
\end{aligned}
$$

Inserting these equations into the transverse resonance equation produces the following equation:

$$
\begin{aligned}
& 2 k n_{f} W \cos \theta-2 \tan ^{-1}\left[\frac{\left(n_{f}^{2} \sin ^{2} \theta-n_{c}^{2}\right)^{k /}}{n_{f} \cos \theta}\right] \\
& -2 \tan ^{-1}\left[\frac{\left(n_{f}^{2} \sin ^{2} \theta-n_{s}^{2}\right)^{k /}}{n_{f} \cos \theta}\right]-2 m \pi
\end{aligned}
$$


$m$ refers to the propagating mode number and, because the waveguide is thin and the index differences are small, waveguiding occurs only at discrete values of $\theta$. These discrete angular values define each waveguide mode. Note for a single mode waveguide $m=0$ and waveguiding occurs at only particular value of $\theta$. Furthermore, for a guided optical wave propagating in the $z$ direction, its complex electric field is

$$
E(x, y, z)-E_{m}(x, y) \exp \left(-j B_{m} z\right)
$$

$B_{m}$ represents the propagation constant for the guided beam and is defined by the following equation:

$$
\begin{array}{r}
B_{m}-k n_{f} \sin \Theta-k N_{e f f} \\
\cdot \\
k-2 \pi / \lambda
\end{array}
$$

where

and

$$
N_{\text {eff }}-n \sin \theta
$$

$\mathrm{N}_{\text {eff }}$ is referred to as the "effective mode index" for the guided beams and represents an effective refractive index for the particular guided optical mode. Its value is also dependent on $\theta$. Examining equation (1), if $n_{f}, n_{s}$ and $W$ are held constant while $n_{c}$ is varied (i.e. a refractive index change due to a chemical interaction), then only $\theta$ can be varied to satisfy the equation. Thus using equations (1) and (8), the sensitivity of the guided beam to changes in the cover film index can be determined and more importantly, the waveguide may be designed to maximize sensitivity to the cover film.

\section{Interferometer Sensitivity}

The previous analysis only describes the phase shift induced in the guided beam by changes that occur in the cover medium. Detection of that phase shift is accomplished using the interferometric techniques where phase shift is translated into an intensity change or fringe shift. To analytically evaluate the sensitivity of the waveguide interferometer requires the use of the dispersion relationship and the standard interferometer equations. First a minimum detectable intensity chang of the interferometer output is established and then the corresponding effective mode index change $\left(\Delta \mathrm{N}_{\text {eff }}\right)$ is calculated using the interferometer. Through the dispersion relationship, the corresponding cover index change is then determined for a particular waveguide system. 
The output of the wave zuide interferometer is described by the following equation;

$$
I-\frac{I_{0}}{2}\left[1+\cos \left[\frac{\pi}{2}+\frac{2 \pi}{\lambda} L\left(\Delta N_{e s j}\right)\right]\right.
$$

where

$$
\begin{aligned}
& \mathrm{I}_{0}=\text { peak intensity } \\
& \lambda=\text { free space wavelength of guided light, } \\
& \mathrm{L}=\text { interferomete: signal arm length, } \\
& \mathrm{N}_{\text {eff }}=\text { effective index of the zero order mode, } \\
& \text { and } \quad I=\text { the output intensity of the interferometer. }
\end{aligned}
$$

With passive detection schemes, intensity changes of $0.1 \mathrm{I}_{0}$ are easily detected at the half power point of a sinusoidal intensity curve. For an interferometer with a two centimeter pathleigth, the latter results in a minimum detectable phase shift of $0.064 \pi$ radians or a $\Delta \mathrm{N}_{\text {eff }}$ of $1 \times 10^{6}$. This corresponds to a change in the cover index, $\Delta \mathrm{n}_{\mathrm{c}}, 5 \times 10^{-6}$ for a waveguide with $\mathrm{W}=7 \mu \mathrm{m}$, $n_{f}=1.580000, n_{1}=1.457000$ and $n_{c}=1.550000$. Thus, the interferometric system is extremely sensitive to small changes in the cover medium. Active detection schemes offer even greater sensitivity potential.

\section{Chemically Selective Coatings}

Two approaches were taken to develop an integrated optic planar waveguide chemical sensor to detect $\mathrm{NH}_{3}$ gas. One relied on a colorimetric change of a $\mathrm{pH}$ indicator causing a measured change in absorption (absorption sensor). This change applied to the absorption of red light in the presence of a pH greater than 7.0. The coating is absorptive in that it will absorb or desorb $\mathrm{NH}_{3}$ in equilibrium with the surrounding environment. The other used the index of refraction change from a chemical interaction to effect an interferogram (interferometric sensor).

\section{Design - Absorption Sensor}

The absorption sensor borrowed from the work of Guiliani et al. (1983). The sensor developed consisted of a fiber optic coated with a $1 \mu \mathrm{m}$ layer of oxazine 720 perchlorate (I). This compound absorbs red light in the acid form but not in the basic form. Since $\mathrm{NH}_{3}$ is a strong base, it was postulated that this device could be used to detect $\mathrm{NH}_{3}$ as no red light would be absorbed in its presence. This transmission change is near a maximum at the 632.8 laser line of the HeNe laser, however, Guiliani used a LED centered at $560 \mathrm{~nm}$ where this change is not as pronounced. Guiliani could detect $\mathrm{NH}_{3}$ down to $10 \mathrm{ppm}$, however, the time constants for detection and reversibility were slow (minutes). Detection and reversibility were apparently limited by diffusion of the $\mathrm{NH}_{3}$ in and out of the sensing layer. With a $10,000 \AA$ thick layer these times are obviously slow. The other problem encountered by Guiliani was that the proton transfer was humidity sensitive. Therefore, the data were taken under constant humidity. 


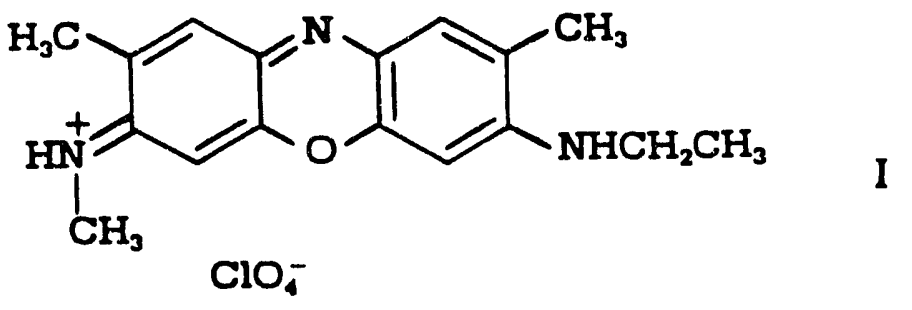

The first set of experiments were to take the oxazine dye Guiliani used and determine if there were any benefit from using a planar waveguide configuration. Analysis indicated that since most of the evanescent field lies very close to the waveguide surface, a much thinner sensing layer could be used on a planar waveguide and thereby improve response time.

The waveguides used consisted of a BK-7 glass substrate in which silver ions are exchanged with sodium ions to provide the refractive index change necessary for waveguiding. To accomplish this, the BK-7 substrates were placed in a molten salt bath consisting of 0.25 molar \% AqNO3 in $\mathrm{NaNO}_{3}$ at $\left(617^{\circ} \mathrm{F}\right) 325^{\circ} \mathrm{C}$ for 20 minutes and then annealed for 20 minutes at $932^{\circ} \mathrm{F}\left(500^{\circ} \mathrm{C}\right)$. The guides typically had one or two possible modes of propagation. Indexes of refraction were measured for the various waveguide modes and ranged from $1.521-1.523$ (BK-7 is 1.515). The sensing coating geometry was defined on the waveguide by masking one half of the waveguide. A dilute solution of oxazine 720 perchlorate in methanol was applied to these waveguides. After a few drops were applied, the waveguide was spun at several hundred rpms for 5 seconds to distribute an even coating.

The first coated waveguide used a $4 \times 10^{-4} \mathrm{M}$ solution of the oxazine. The waveguide had a slight blue tint after spinning. The light from a HeNe laser was split by a beamsplitter and the parallel beams were coupled into the waveguide with a prism (Figure 6). One beam passed under the oxazine coating, the adjacent beam provided a reference passing through an uncoated section of the waveguide. Response to $\mathrm{NH}_{3}$ was determined qualitatively using a wash bottle containing a saturated ammonium hydroxide solution. The $\mathrm{NH}_{3}$ used came from the saturated head space above this solution. The first coated waveguide responded instantaneously with application of $\mathrm{NH}_{3}$ and rernained fairly constant as long as the stimulus was provided. Recovery began immediately upon removal of the $\mathrm{NH}_{3}$. The response was characterized by an increase in transmission of the guided wave (reduced absorption) in the presence of $\mathbf{N H}_{3}$. The slow response after removal is due to: 1) lack of a mechanism to remove the $\mathrm{NH}_{3}$ molecule and 2) diffusion through the film. Therefore, the return to baseline was slower than the rise time (Figure 7) and response times were improved with a thinner coating layer. The optimum concentrations of the coating solution was found to be $4 \times 10^{-5} \mathrm{M}$ or $17 \mu \mathrm{g} / \mathrm{ml}$ of the oxazine. When this solution was spun onto the waveguide, no visible color was seen. Several techniques were employed to measure the thickness of the coating applied to the waveguide. However, no instrument measurement was capable of characterizing the thickness of the coating layer. The only indication there was anything on the waveguide was its sensitivity to $\mathbf{N H}_{3}$.

To further enhance the oxazine based detector, a lower index waveguide was tried. Lowering the index allows the evanescent field to interact more efficiently with the sensitive coating. The lower index waveguides were prepared from Schott BGG 21 glass which had been ion exchanged with cesium nitrate at $788^{\circ} \mathrm{F}\left(420^{\circ} \mathrm{C}\right)$ for 30 minutes. This provided a waveguide with two modes with indices of 1.475 and 1.481. Coating these low index waveguides with the $4 \times 10^{-5} \mathrm{M}$ oxazine solution provide a fast response and enhanced sensitivity (Figure 8). One problem observed with the oxazine was its response to water vapor. When moist air was used in place of $\mathrm{NH}_{3}$, an increase, though much smaller than $\mathrm{NH}_{3}$, in transmission was measured. 
When dry air was blown over the layer, the transmission decreased. Visually the dry air caused an increase in scattering by the oxazine c:ystals on the surface. Oxazine being a large planar molecule with little internal degrees of freedom would have a tendency to form microcrystallites. The humid air, in theory, helps dissolve and randomize the individual molecules. Ammonia in a dry stream produced an effect equal and opposite from that of moist $\mathrm{NH}_{3}$ presumably due to a drying effect. Obviously the change in humidity at the extremes has an effect on response. Though these problems with the oxazine were not overcome, this work did provide data used in designing the interferometric sensing moiety.

\section{Dynamic Testing - Absorption Sensor}

For quantitative results, the absorption sensor was subjected to a series of dynamic tests. Dynamic testing was performed by subjecting the exposed surface of a test waveguide to an airstream created by the gas mixing system illustrated in Figure 9 . Airstream relative humidity and $\mathrm{NH}_{3}$ concentration were the only two variables evaluated during these tests. Airstream temperature and flow were maintained fairly constant at $75^{\circ} \mathrm{F}\left(24^{\circ} \mathrm{C}\right)$ and $1 \mathrm{lpm}$, respectively, for the duration of these tests.

Dynamic testing for the different sensor configurations and coatings was conducted after the aforementioned qualitative testing yielded encouraging results. The testing method involved an incremental increase in $\mathrm{NH}_{3}$ exposure beginning in the low ppm range to determine the lower range of sensitivity of a particular device. Each test series was performed by stabilizing airstream humidity, flow, and $\mathrm{NH}_{3}$ concentration at a set level and allowing the air system time to stabilize (roughly 20 minutes). The sensor waveguide was then exposed to the airstream by gently waving a tube carrying the airstream $1-1.5$ in $(3-4 \mathrm{~cm})$ over the waveguide surface. Each exposure was repeated 3-5 times during a test run.

The qualitative results of these dynamic tests for the absorptive sensor using an oxazine 720 perchlorate coating are summarized in Table 1. It was determined early (Test 1-12) that the oxazine device exhibited a somewhat linear response from exposure to varying levels of $\mathrm{NH}_{3}$ in the dynamic airstream. Moreover, the sensor indicated a humidity effect, a condition somewhat expected from the qualitative tests and previous research (Guiliani et al. 1983). This effect highlighted the need to maintain airstream humidity near room ambient humidity to remove this parameter as a variable while conducting $\mathrm{NH}_{3}$ exposure tests.

As shown in the grapn in Figure 10 , a waveguide coated with $10^{-5} \mathrm{M}$ oxazine 720 perchlorate exhibited a somewhat linear relationship over an exposure range of 0 to $155 \mathrm{ppm}$ $\mathrm{NH}_{3}$ in air. A linear regression of the sensor response (\% transmission) to $\mathrm{NH}_{3}$ concentration in air revealed a regression coefficient of 0.7371 . In the course of this series of test exposures, the relationship between sensor output variation and a shift in airstream relative humidity became more apparent.

During the next successful series of tests (Test 75-81), airstream humidity was maintained near room humidity to lessen these humidity effects. As illustrated in Figure 11, the response of the sensor to changes in airstream $\mathrm{NH}_{3}$ concentration was very stable and proportional to the increase in $\mathrm{NH}_{3}$. A linear regression of the two variables (sensor output and $\mathrm{NH}_{3}$ concentration) yielded a regression coefficient of 0.6875 . Visually, however, the sensor exhibited a very linear response with the exception of one average test point at $25 \mathrm{ppm}$. This regression yielded that an increase of $1 \mathrm{ppm} \mathrm{NH}_{3}$ in air would result in an increase in sensor output of $2.14 \times 10^{-3} \mu \mathrm{W}$.

In Test $82-89$, the relative humidity of a clean airstream (no $\mathrm{NH}_{3}$ ) was varied between 43 and $73 \%$ while the room relative humidity was maintained at $63 \%$. The results illustrated 
in Figure 12 indicate a strong linear relationship between airstream relative humidity and sensor output $\left(R^{2}=0.9791\right)$. Sensor output changed $-4.99 \times 10^{-2} \mu \mathrm{W}$ per relative humidity percentage point shift up from the room relative humidity standard. When compared to the response of this same sensor to changes in $\mathrm{NH}_{3}$ concentration in air, a positive shift of one relative humidity percentage point would have the same impact as a negative shift of $23 \mathrm{ppm}$ of $\mathrm{NH}_{3}$ in air.

\section{Design - Interferometric Sensor}

In the interferometric configuration, detection does not require a color change but a change in refractive index. This change is caused by a phase shift between light modes as previously discussed. Chemical reactions roduce changes in the refractive index. This allows a wide array of possible sensing compounds owing to the many variations organic chemistry can provide. This number is slightly limited if the reaction is to be reversible. With $\mathrm{NH}_{3}$ being a fairly strong base, the most obvious reaction to employ as a sensor would be proton transfer. The choice of compounds would depend on the pKa's. The $\mathrm{Ka}$ is the equilibrium constant for the protoit transfer between water and the protonated base in the reaction,

$$
\mathrm{BH}^{*}+\mathrm{H}_{2} \mathrm{O}=\mathrm{B}+\mathrm{H}_{3} \mathrm{O}^{+}
$$

and the $\mathrm{pKa}=-\log \mathrm{Ka}$. The larger the $\mathrm{Ka}$, the stronger the base and the weaker it's conjugate acid and vice versa. $\mathrm{NH}_{3}$ has a pKa of 9.25 (Weast 1985) which means the proton source would have to come from the conjugate acid of a base with the same or lower pKa. This led to the testing of two classes of compounds: phenols which have similar pKa's and aniline- $\mathrm{H}^{+}$salts which have much lower pKa's. The acid could not be too strong otherwise the reversibility would be jeopardized. The reaction of phenols with $\mathrm{NH}_{3}$ is:

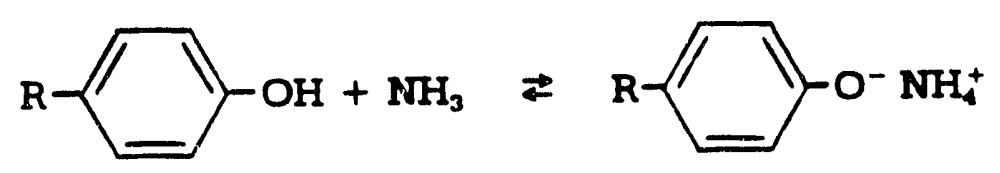

and the reaction of aniline salts is:

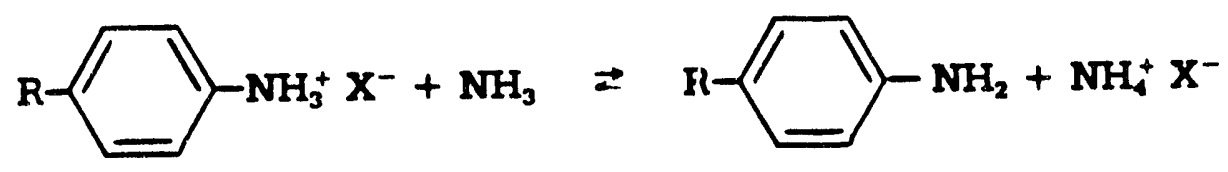

Two additional factors in the choice of tesi materials were considered. First, in order to suppress the light scattering effects seen in the oxazine with humidity change, large hydrocarbon chains were added to the phenyl ring to increase the internal degrees of freedom thereby lessening tendency of the molecule to crystallize. Second, which was a consequence of the first, 
increasing the molecule weight decreased the volatility of the free base so the sensing moiety did not evaporate with time and use. These factors resulted in the selection of the longer carbon chain molecules for the coating materials.

Coated waveguides were prepared using the same procedure used for oxazine. The optical setup, however, is different as illustrated in Figure 13. In the interferometer, the two adjacent beams are combined by a lens after passing through the waveguide. The overlap region containing the interference pattern is magnified and projected by a second lenr on to a detector with a narrow slit. The slit is arranged parallel to the interference lines and the magnification is adjusted so that the slit width is only a srnall fraction $(1 / 10)$ of an actual fringe period. If a chemical reaction occurs in the coated pach, then the phase of the sensing beam is either retarded or advanced. This will in turn shift the interference pattern. The resulting fringe shift is reflected as an intensity change either positive or negative depending on the phase change.

The two phenols tried, 4-tert octylphenol (II) and 4-tert butylcalix(4)arene (III) have pKa similar to $\mathrm{NH}_{3}$. These showed no response. This made it apparent that in order to produce a response the pKa has to be much lower than that of $\mathrm{NH}_{3}$. The conjugate acids of aniline were the next set of compounds tested. Aniline has a pKa of 4.6 (Weast 1985) making it a 40,000 times weaker base than $\mathrm{NH}_{3}$ and should, as the conjugate acid, provide enough acid strength to transfer the proton to $\mathrm{NH}_{3}$. It may seem as though the transfer would not be reversible because of the disparity in base strengths but evaporation of the $\mathrm{NH}_{3}$ drives the equilibrium to completion. This gives back the aniline salt after the $\mathrm{NH}_{3}$ stimulus is removed.

A series of 4-substituted anilinium salts were prepared from the 4-substituted anilines and anhydrous hydrogen chloride in diethyl ether. The precipitated salts were recrystallized from either methanol/toluene or chloroform/toluene. A long alkyl group at the 4-position should provided the floppy group needed to inhibit crystallization. The compounds made were the 4-nhexyl- (IV-a), 4-n-octyl- (IV-b), 4-n-dodecyl- (IV-c), 4-n-tetradecyl- (IV-d) and 4-n-hexadecylanilinium (IV-e) chlorides (all having about the same pKa). In addition, the 4-n-hexyloxyanilinium anilinium chloride $(V)$ was prepared, yielding a compound with 10 times less acid strength than the other anilines due to the electron donating character of the ether linkage. These compounds were dissolved in ethanol, spin applied, to either BK-7 or BGG 21 waveguides, setup as an interferometer and tested for $\mathrm{NH}_{3}$. Four things become apparent from the testing: 1) the BGG 21 low. index waveguides provided higher sensitivity as was found for the oxazine case, 2) as the length of the alkyl chain increases the amount of scattering decreases, 3) the concentration of the compounds applied did not have to be higher than a few milligrams per ml, and 4) a weaker base/stronger conjugate acid could increase sensitivity many fold.

Though initial screenings were done on BK-7 waveguides, all subsequent work was done on the lower index guides because of its higher sensitivity and longer interaction length $(2 \times \mathrm{BK}$ 7). The increased sensitivity is due primarily to the increased overlap of the evanescent field of the guided wave with the surface film. Though scattering decreased in the humidity cycling from hexyl to longer chains, no substantial improvement resulted past dodecylanilinium chloride. Because increasing the alkyl "baggage" provided no apparent benefits, these results suggested concentrating the investigations on the dodecylanilinium salt.

Solutions of $4-n$-dodecylanilinium chloride were applied to the waveguide to find an optimum coating thickness over a range of concentrations. Starting with $4.6 \mathrm{mg} / \mathrm{ml}(1.6 \times 10$ ${ }^{2} \mathrm{M}$ ) solution, this film yielded an obvious white appearance to the waveguide and had very little sensitivity. Decreasing concentration to $0.96 \mathrm{mg} / \mathrm{ml}$ gave a waveguide with no appearance of a film but did show sensitivity to both moisture and anhydrous $\mathrm{NH}_{3}$ and in the same direction 
<smiles>CCC(C)(C)Cc1ccc(O)cc1</smiles><smiles>CCc1cc(C(C)(C)C)cc(CC2CCCCCCC2)c1O</smiles>

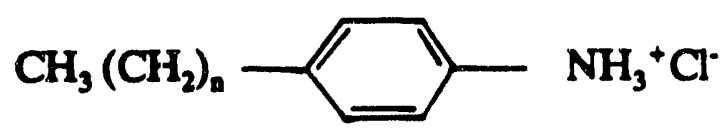
a) $n=5$
b) $n=7$
c) $n=11$
d) $n=13$
e) $\pi=15$

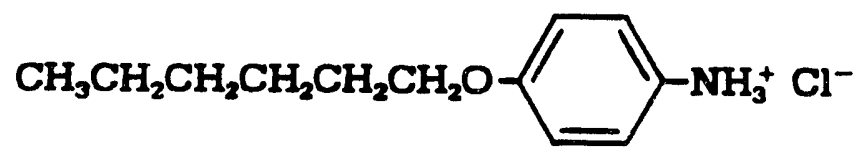

(as opposed to the oxazine case). Sensitivity increased with the $0.19 \mathrm{mg} / \mathrm{ml}(190 \mu \mathrm{g} / \mathrm{ml})$ solution and $0.038 \mathrm{mg} / \mathrm{ml}(38 \mu \mathrm{g} / \mathrm{ml})$ solutions. With the $7.6 \mu \mathrm{g} / \mathrm{ml}\left(2.6 \times 10^{-5} \mathrm{M}\right)$ solution sensitivity was a little less than the $38 \mu \mathrm{g} / \mathrm{ml}$ solution. If one calculates the amount of material put down using a $7.6 \mathrm{mg} / \mathrm{ml}$ solution by assuming a liberally high thickness of the solution on the surface after spinning of $1 \mu \mathrm{m}$, upon drying one achieves a layer consisting of only a fraction of a monolayer. Apparently the material is concentrating on the surface through some self-assembly or adhesion even before spinning and is impeded only by the amount of materials in concentration at the start and the amount of contact time. The quantitative measurements employed a dodecylanilinium chloride solution in the $40 \mu \mathrm{g} / \mathrm{ml}$ range. 
Throughout these tests, not only was the response to $\mathrm{NH}_{3}$ (wet and dry) checked but, also, the response to methylamine was monitored. Methylamine has a pKa of 10.6 (Weast 1985) making it 20 times more basic than $\mathrm{NH}_{3}$. In all cases (oxazine and anilinium salts), the sensors response to methylamine was an order of magnitude greater than with $\mathrm{NH}_{3}$ (Figure 14). This points out that if a weaker base, i.e. stronger conjugate acid, was used instead of the 4-ndodecylanilinium chloride, the response to $\mathrm{NH}_{3}$ could be greatly improved. However, location and synthesis of this type of material was beyond the time constraint: of this project and more readily available materials, such as the dodecylanilinium chloride, were used. A 40,000/1 basic strength difference would appear to be more than necessary to effect efficient proton transfer but the methylamine data coupled with the lack of response from the 4-n-hexyloxyanilinium chloride $\left(1 / 8,000 \mathrm{NH}_{3}\right)$ indicates that increasing this ratio can only improve sensitivity.

Finally, one problem repeatedly occurred. Within a few hours to several days, the sensing layer would loose some or all of its sensitivity. Two possible causes were suspected. One, during the proton exchange back and forth between the $\mathrm{NH}_{3}$ and the aniline some of the $\mathrm{HCl}$ is lost. Like $\mathrm{NH}_{3}, \mathrm{HCl}$ is a gas so possibly the $\mathrm{HCl}$ could be lost slowly as a molecular species. This would lead to the sensing layer consisting of aniline as the free base being incapable of responding to $\mathrm{NH}_{3}$. The other cause of the problem may crme from the cleaning of the glass waveguides. Typically, the waveguide was cleaned with Microclean ${ }^{\star}$. Microclean ${ }^{\bullet}$ contains a strong base, triethanolamine, which could either open up basic sites on the glass or remain as residual base on the surface, both tying up the $\mathrm{HCl}$. This latter cause was countered by washing the waveguide with sulfuric acid. This left an acidic surface before the coating and improved the lifetime of the sensor. However, the sensor sensitivity would still eventually decrease. To circumvent the possible loss of $\mathrm{HCl}$, a different acid salt, in which the free acid has no vapor pressure, was used. A di(4-n-dodecylanilinium) sulfate was prepared from 4-ndodecylaniline and sulfuric acid in diethyl ether. The sulfate salt was purified by recrystallization from methanol. This salt was not very soluble in methanol or ethanol. Enough, however, was soluble to spin coat the waveguide. The combination of the acid n'ash and the sulfate salt improved long term stability.

\section{Dynamic Testing - Interferometric Sensor}

Dynamic tests were also performed on an interferometric sensor system using various waveguide preparations. The methodology used in performing these tests were identical to those used in testing the absorption sensors. The summary of the notes from these tests are provided in Table 2. Early dynamic tests (Test 13-55) yielded mixed results. Sensor stability and sensitivity seemed to vary with waveguide preparation (dodecylanilinium chloride). During this series of tests, the sensor seemed at times to be responsive to exposure to moderate levels (40 ppm) of $\mathrm{NH}_{3}$ in air; however, no specific pattern could be detected. Furthermore, the sensor typically exhibited a continuous drift making detection of a signal shift difficult.

After acid washing of the waveguide was suggested, a series of tests were conducted (Test 90-96). The sensor seemed to be responsive to exposure to $\mathrm{NH}_{3}$ although the response to changes in concentration were non-linear. Moreover, the sensor seemed to also be sensitive to shifts in relative humidity. Problems with maintaining room environmental conditions led to cancellation of the test series.

Additional tests were conducted a few days later with s similar coating and the acid rinse waveguide preparation (Test 98-109). As illustrated by the average response (phase shift, $\pi$ radians) plot in Figure 15 , the sensor exhibited a somewhat linear response $\left(R^{2}=0.7288\right)$ to 
changes in $\mathrm{NH}_{3}$ concentration up to $24 \mathrm{ppm}$. The sensor may have been more sensitive to lower concentrations of $\mathrm{NH}_{3}$; however, signal noise prevented this level of detection. The regression yielded that an increase of 1 ppm $\mathrm{NH}_{3}$ in air would result in an increase in phase shift of $2.06 \times 10^{-3} \pi$ radians. It was noted in these tests that a phase shift was detected when the waveguide was exposed to an airstream with zero $\mathrm{NH}_{3}$ (Figure 15). This experimentally induced error was likely due to the effects of air moving across the surface of the waveguide and changing the moisture equilibrium in the thin film.

A series of tests (Test 102-107) were conducted to determine the sensitivity of the sensor to changes in airstream relative humidity. As illustrated in Figure 16, the sensor yielded a fairly linear response $\left(R^{2}=0.9745\right)$ to changes in relative humidity between 54 and $88 \%$ relative to room humidity $(71 \%)$. The regression also yielded a phase shift of $4.04 \times 10^{-3} \pi$ radians per relative humidity percentage unit. Compared to the response of this same sensor to changes in $\mathrm{NH}_{3}$ concentration in air, a positive shift of one relative humidity percentage point would have the same impact as a positive shift roughly $2 \mathrm{ppm}$ of $\mathrm{NH}_{3}$ in air. The impact indicates the possible need to nullify the effects of shifting humidity levels around the sensor; however, the humidity impact is an order of magnitude less than that experienced with the absorption sensor using oxazine 720 perchlorate. Moreover, the phase shift related to a positive change in humidity was in the same direction as the phase change due to an increase in $\mathbf{N H}_{\mathbf{3}}$.

While a some', hat linear response to $\mathrm{NH}_{3}$ concentrations was shown by the dodecyianilinium chloride, sensor stability over short periods of time was very suspect. To offset this problem, a waveguide was coated with dedecylanilinium sulfate in an attempt to better stabilize the sensor. A series of tests were conducted (Test 110-117 and Test 118-126) on this sensor as suriutuarized in Table 2. The tests indicated that, contrary to previous static testing, this sensor had even less stability than the previous setup and was more sensitive to extraneous parameters (ie. air movement).

$\mathrm{NH}_{3}$ exposure tests were repeated for a sensor with a waveguide coated with dodecylanilinium chloride (Test 128-133 and Test 134-137) as summarized in Table 3. A linear regression of the average response data indicated a fairly high level of linearity for both tests as illustrated in Figures 17 and $18\left(R^{2}=0.9624\right.$ and 0.9745 , respectively). The regression also yielded a phase shift of 1.74 to $1.97 \times 10^{-4} \pi$ radians per $\mathrm{ppm}$ of $\mathrm{NH}_{3}$ in air, an order of magnitude less sensitive than indicated by previous tests (Test 98-109). Another set of tests (Test 138-148) yielded an even lower sensitivity with a regression coefficient of $2.70 \times 10^{5} \pi$ radians per ppm $\mathrm{NH}_{3}$ (Figure 19). The linearity of the device, however, was still high $\left(\mathrm{R}^{2}=0.9852\right)$.

\section{Discussion}

To improve the performance of the waveguide $\mathrm{NH}_{3}$ sensor, sensitivity and durability should be further explored. Both the absorption and interferometric configurations could be improved by looking into these two considerations. To improve sensitivity the pKa of the sensing base needs to be lowered to increase the proton transfer. Locating and synthesizing this material could take some time. Oxazine's $\mathrm{pKa}$ is similar to that of aniline's. To lower the pKa of oxazine is no simple task but there are other $\mathrm{pH}$ indicators which could be used with lower pKa but this may require a change in laser frequency since the coloromatic change may not be at the HeNe laser line. To change the $\mathrm{pKa}$ of the aniline is a bit easier. Various derivative of 4-n-alkylaniline can be synthesized which have lower pKa's, for example, the 3-chloro and 2- 
chloro derivatives with pKa's of 3.5 and 2.7 (Weast 1985), respectively, could give 10 to 100 fold increase in sensitivity if the response remains linear with pKa. With this kind of increase in $\mathrm{NH}_{3}$ sensitivity, the problems associated with water vapor would be inconsequential.

We have already shown that to increase durability one needs to start with a nonbasic substrate and also that the nature of the counterion is important. The councerion can also play a role in desensitizing the humidity effects on the layer by whether the ion is hygroscopic or not. The more water that can be associated with the layer the less sensitive to humidity change the layer should be. For field use, one would want a sensing layer that could also put up with the rigors of the outdoors. There are three ways to accomplish this: the sensing moiety could be dissolved in a polymer matrix, the sensing group could be placed in the backbone of the polymer or the sensing compound could be Langmuir-Blodgett monolayered (and possibly polymerized after that). The !.angmuir-Blodgett approach would also provide a clue as to the thickness of ti ese sensing layers which has eluded measurement so far. This ability to caliper the layer is possible because the LB films are of precise molecular dimension. These layers can be assembled systematically with a dimensional increase of between $10-20 \AA$ per layer. A correlation between the number of monolayers and the sensitivity to $\mathrm{NH}_{3}$ will help truly understand the working of this sensor.

From an instrumentation viewpoint, increased detection sensitivity would be possible by utilizing a fully integrated interferometric configuration. As previously noted, the laboratory waveguide test device utilized a separate beam splitter and combiner. By integrating these two elements, interferometer noise and drift would be reduced approximately an order of magnitude. This would provide an additional increase in sensitivity by about a factor 10 over the already sensitive laboratory device due to reduced noise and drift.

\section{Summary}

Progress has been made in identifying waveguide coating materials for use on both an absorption and interferometric device. A thin-film oxazine dye has been demonstrated to indicate ammonia levels in air in the $10-100 \mathrm{ppm}$ range. However, as indicated in previous research with oxazine dyes as an indicator, the device is very humidity dependant. It is believed that this humidity effect is predictable and can be minimized by changing the waveguide design.

An aniline salt coating on an interferometric device has also been demonstrated as being sensitive to ammonia levels in air in the $10-100 \mathrm{ppm}$ range; however, two problems have arisen that require further study. First, the device as configured on on isolated optical table with multiple optical components is very sensitive to noise. Therefore, the signal from the device has been subject to drift. Second, the device apparently is somewhat humidity dependent. Both problems should be remedied with the construction of an integrated device incorporating a MachZehnder configuration to optically cancel any humidity effects.

With both devices, it is believed that sensitivity and range will improve with the deposition of the waveguide coatings with a molecular bonding technique such as LangmuirBlodgett. 


\section{APPLICATION OF TECHNOLOGY}

\section{Sensor Application Concepts}

As indicated in the previous section, there is a strong potential to develop a field worthy IO sensor capable of measuring $\mathrm{NH}_{3}$ in parts per million and possibly parts per billion. The function of such a sensor could potentially be to:

- Improve the application efficiency of anhydrous $\mathrm{NH}_{3}$ and low-pressure liquids by monitoring losses during application and taking corrective measures to reduce them, and

- Enhance the utilization of $\mathrm{N}$ fertilizers by a crop by monitoring losses over time and applying fertilizer relative to those losses and other crop/soil information.

Application of this technology' will depend primarily on the lower detection limit of a sensor, sensor cost, and the value of the information from the sensor. For example, if a sensor has a lower detection linit of only $1 \mathrm{ppm}$, it would not be capable of monitoring $\mathrm{NH}_{3}$ fluxes from soils during the days after fertilizer application. It would, however, be useful as a monitor of immediate soil losses following the injection of anhydrous $\mathrm{NH}_{3}$. Conversely, if a sensor did have a lower detection limit of 1 ppb it could be used in-situ to monitor soil $\mathbf{N H}_{3}$ fluxes. However, should the cost of this type of sensor be too high (ie. $\$ 1,000$ ), it would not be economically viable to place these sensors in the field within any practical density (ie. one sensor per 10 acres). Lastly, the sensor must provide information that has value, simply providing data is not enough to justify its existence. For example, monitoring the $\mathrm{NH}_{3}$ losses from the soil immediately after anhydrous injection would not be of any value unless the operator or system controller could make an adjustment in either the rate of application or the depth of application. Moreover, monitoring low level soil/crop $\mathrm{NH}_{3}$ fluxes over a period of time is relatively meaningless unless the data can be used by a crop scientist or specialist in conjunction with other data input to make fertilizer management decisions that improve efficiency and/or productivity. With these arguments in mind, the following application concepts have been developed:

Mobil (post-application). A sensor with a minimum detectable limit of 1-10 ppm would be mounted on a tool bar pulled behind an anhydrous applicator (Figure 20). The sensor would provide real-time data on applicator and soil $\mathrm{NH}_{3}$ losses which could be corrected by direct control of the anhydrous flow, tractor speed, and injector settings (ie. depth). At a minimum, sensor data could serve to advise the operator to wait for better soil and weather conditions in which to apply. A potential limit to this application would include the variability in the rate of $\mathrm{NH}_{3}$ evolution due to soil and weather conditions.

Mobil (pre-application). A sensor with a minimum detectable limit of 1-10 ppb would be mounted with a soil ripping device to sense the evolution of $\mathrm{NH}_{3}$ released as the tool breaks the soil surface, a "scratch and sniff" approach. The sensor might be mounted just above the soil surface or might be encased in a small head space that will dynamically capture soil gases as they are released during the plowing of the surface (Figure 21). If the $\mathrm{NH}_{3}$ release can be tied back to $\mathrm{N}$ demand within the cropping system, the information from the sensor could be used as a control input to a fertilizer 
applicator system immediately following the sensor. A limit to this application is that the correlation of $\mathrm{NH}_{3}$ release from a disturbed soil and $\mathrm{N}$ demand in that soil has not been developed and would be very difficult to develop.

In-Situ. Sensors with a minimum detectible limit of 1-10 ppb would be placed at different levels ranging from slightly imbeded in the soil to a few feet above the soil surface to monitor $\mathrm{NH}_{3}$ fluxes from a crop/soil system (Figure 22). The information could be used with other environmental and analytical data to cetermine an optimum fertilizer strategy based on dosing the crop with the right amount of fertilizer at the right time. Limits to this application include the need to establish a database or history for the particular crop and soil system with which to compare to make these management decisions.

\section{Assessment of Energy, Economic, and Environmental Factors}

The viability of the continued development of the $\mathrm{NH}_{3}$ sensor involve both energy and economic factors. The energy factors are of importance to the U. S. Department of Energy since the objective for funding the project is to reduce the amount of energy used for production of $\mathrm{N}$ based fertilizers. The economic factors are of importance to the farmer, extension agent, co-operative, or other customer for the sensor since the unit must be economically viable or it will not be purchased. However, these two factors are directly related because a reduction in the amount of fe.tilizer used in agriculture will save the energy required for production and the cost of fertilizer to the farmer.

From an environmental perspective, conservation of $\mathrm{N}$ based fertilizers translates into less available material that could leach into groundwater as a nitrate or runoff into surface waters as an $\mathrm{NH}_{4}{ }^{+}$. Moreover, the sensor could be used in monitoring and controlling the land application of high $\mathrm{N}$ wastes and wastewaters providing additional protection to surface and groundwaters.

\section{Cost of Fertilizer and Production Energy}

The computation of the energy for production and cost of $\mathrm{N}$-based fertilizer is presented in Table 3. Chemical \& Engineering News (1991) provided the data on the production of Nbased fertilizer in the United States in calendar year 1990, and these data are shown in the total production column in Table 3. The 23,372 thousand tons accounts for $83.1 \%$ of the $\mathrm{N}$ products produced. The balance accounts for miscellaneous $\mathrm{N}$ solutions which was not included in the analysis because data for energy for production and selling price could not be identified. Therefore, the estimates for energy and purchase price savings will be conservative.

The data indicate that $60.6 \%$ of the total $\mathrm{N}$-based fertilizer produced in 1990 was anhydrous $\mathrm{NH}_{3}$ confirming eariler data $(65 \%)$ by Englestad et al. (1985). The remaining $39.4 \%$ of the production account for ammonium nitrate, ammonium sulfate, and urea which are solid fertilizers.

The Chemical Marketing Reporter (1991) provided the current data on selling price of the five types of fertilized being considered in this analysis. As previously discussed, the reference did not contain information on $\mathrm{N}$ solutions. The cost for anhydrous $\mathrm{NH}_{3}$ on a per ton basis is the highest of the five fertilizers evaluated ( $\$ 145 /$ ton). Since the unit cost and the production of anhydrous $\mathrm{NH}_{3}$ are the highest the total selling price is also the highest. The analysis indicates that the total selling cost of the five fertilizers analyzed is 3.19 billion dollars. 
Boswell et al. (1985) determined the energy for production of the five fertilizers being analyzed and the data are presented in Table 3 . The production and energy for production were used to compute the total cost for production. These data are presented lit both trillion Btu and Quads (quadrillion or $10^{15} \mathrm{Btu}$ ) in Table 3. The analysis indicates that 0.779 Quads are used in the production of the five fertilizers.

EIA (1991) reported a total of 20.534 Quads were consumed by the industrial sector in 1988. The Chemical and Allied Products Industry (Standard Industrial Classification (SIC) Code 28) consumed 4.36 Quads in 1988. The analysis presented in Table 3 indicates that the energy for production of the five fertilizers accounted for approximately $3.8 \%$ of the national consumption and $17.9 \%$ of the chemical industry consumption. Therefore, reduction in the use of $\mathrm{N}$-based fertilizer could have a significant impact on energy consumption.

\section{Sensor Cost}

The cost estimate for the integrated optics sensor are presented in Tabie 4. The costs for these components are well known since these same items were used curring the Phase I research. However, the cost for labor is only a rough estimate which could increase or decrease depending on whether the system can be mass produced or must be built primarily by hand. The profit is also only a rough estimate since the eventual market penetration will determine this value.

\section{Economic Evaluation of a Mobile Sensor}

The evaluation of energy savings and economics for a mobile sensor is presented in: Table 5. The energy savings are based on an estimated $10 \%$ reduction in the amount of anhy.drous $\mathrm{NH}_{3}$ used by a system using a sensor system. Since this sensor has not been field tested, the $10 \%$ va'ue is only an estimate and will be verified during Phase III field testing of this project. A search of existing literature did not identify a usable value for the losses during application and immediately after application due to soil conditions. The $10 \%$ value appeared to be a reasonable estimate for preliminary analyses.

The total anhydrous $\mathrm{NH}_{3}$ fertilizer production, selling price, and production energy savings were taken from Table 4 . Assuming a $10 \%$ reduction, the production savings for anhydrous $\mathrm{NH}_{3}$ would be 0.21 billion dollars. The energy savings would be 0.057 QUADS.

The simple payback arialysis for the purchase of a sensor is also presented in Table 5. The average size of a farm in the United States in 190 was 440 acres (Peseck et al. 1989). As previously discussed, fertilizer ton from 90 to 270 pounds of nitrogen per acre. Assuming the average a anhydrous $\mathrm{NH}_{3}$ of $82.4 \%$, the $\mathrm{G}$. tons) of $\mathrm{N}$ each year. A 10\% twetionin the amount of fritizer puretised and applied would

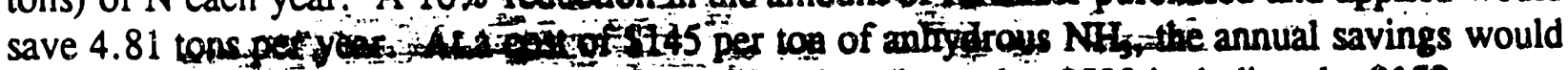
be $\$ 697$. The complete cost of the mobile stinsor is estimated at $\$ 500$ incloding the $\$ 150$ sensor and $\$ 350$ for sensor data readout meter, cabling, and other equipment. The analysis shows that the sensor would payback in 0.72 years representing a $139.4 \%$ retum on investment.

The savings could be considerably higher in other scenarios. For exa.nple, if the farm is 1,000 acres rather than 440 acres, the sensor cost would remain the same and the annual savings would be $\$ 1,585$ resulting in a 0.32 year payback. The farmer who owns a 440 acre farm may not own his own applicator. Instead he may hire a company to apply fertilizer to his land. The company could apply anhydrous fertilizer to many thousands of acres per year using the same applicator and sensor. The total savings in this case would be considerably higher. 
There are several other scenarics that could be used to compute the economics of the mobile sensor. However, the analysis presented in Table 5 for the average farm size indicates that the mobile sensor is economically viable in a typical situation.

\section{Economic Evaluation of an In-Situ Sensor}

The evaluation of energy savings and economics for the in-situ sensor is presented in Tatle 6. As previously discussed, $\mathrm{N}$ losses in the form of $\mathrm{NH}_{3}$ have been measured from 10 to $70 \%$ of the total solid $\mathrm{N}$-based fertilizer originally applied to the soil. Therefore, a $10 \%$ savings attributed to using an in-situ sensor is a conservative estimate. The total solid $\mathrm{N}$-based fertilizer production, selling price, and production energy savings were taken from Table 3. Assuming a $10 \%$ reductic $n$, the production savings for granular $\mathrm{N}$-based fertilizer alone would be 0.11 billion dollars. The energy savings would be 0.021 QUADS.

The simple paybar $k$ analysis for the purchase of a sensor is also presented in Table 6 . The analysis again assumes the use of the in-situ sensor on the average 440 acre farm and the application rate of 180 pounds of $\mathrm{N}$ per acre. Ammonium nitrate was selected for the solid $\mathrm{N}$ based fertilizer in the analysis. Ammonium nitrate is $35 \% \mathrm{~N}$ and therefore 226,286 pounds (113.14 tons; would be purchased and applied each year. A $10 \%$ savings would save $\$ 1,426$ per year in fertilizer purchase costs.

The in-situ sensor system is different from the mobile system in that multiple sensors are required. Using an estimate of 1 sensor for 20 acres and a cost of $\$ 5,000$ for the data collection system, the total sensor system cost would be $\$ 8,300$. The system would have a simple payback of 5.82 years. While the economics of this application are not as favorable as the mobile sensor system, the economics are still viable.

The iristallation of the sensor at a larger farm would result in considerably better economics. For example the installation of the in-situ system at a 1,000 acre farm would require only the purchase of more sensors at a cost of $\$ 150$ each. The $\$ 5,000$ data acquisition system cruld still be used. In this situation, the annual savings in purchase of fertilizer would be $\$ 3,240$ resulting in a payback of 3.86 years.

\section{Summary of Economic and Energy Savings}

These economics data are preliminary at this time. However, these do indicate the sensor is viable from both an energy and cost savings analysis. Therefore, continuation of the sensor development is warranted. The data generated during subsequent phases will provide the additional information needed to refine the energy and economic analyses. 


\section{REFERENCES}

Alferness, R.C. 1984. Ti:LiNbO3 guided wave devices for long wavelength communication. Topical Meeting on Integrated Guided Wave Optics. Paper TUA1.

Boswell, F. C., J. J. Meisinger, and N. L. Case. 1985. Production, marketing, and use of nitrogen fertilizer. Chapter In: Fertilizer Technology and Use. Englestad, O. P. (Ed.). Soil Science Society of America, Inc. Madison, Wisconsin.

Chemical \& Engineering News. 1991. Production by the U. S. chemical industry - 1990. American Chemical Society. Washington, DC. June:36.

Chemical Marketing Reporter. 1991. Schnell Publishing. New York, NY. August 12, 1991.

Clifford, P. K. and D. T. Tuma. 1982. Characteristics of semiconductor gas sensors, steady state response. Final Report: DOE EE-77-S-02-4346.

Davis, C. H. and G. M. Blouin. 1977. Energy consumption in the U.S. chemical fertilizer system from the ground to the ground. In: Agriculture and Energy. Ed. W. Lockeretz. Academic Press. New York. p. 315-331.

Denmead, O. T., J.R. Simpson, and J. R. Freney. 1977. A direct field measurement of $\mathbf{N H}_{3}$ emission after injection of anhydrous $\mathrm{NH}_{3}$. Soil Sci. Soc. Am. J. 41:1001-1004.

Energy Information Agency. 1991. Manufacturing energy consumption survey: consumption of energy 1988. EIA, Office of Markets and End Use, U. S. Department of Energy. Washington, DC.

Englestad, O.P. (editor) et al. 1985. Fertilizer Technology and Use Third Edition, Soil Science Society of America, Inc. Madison, WI

Gaultney, L. D. et al. 1988. Automatic soil organic matter mapping. American Society of Agricultural Engineers. Paper 88-1607. St. Joseph, MI.

Giuliani, J. F. et al . 1983. Reversible optical waveguide sensor for $\mathbf{N H}_{3}$ vapor. Optics Lett. 8 (1):54-56.

Hargrove, W. L. 1988. Evaluation of $\mathrm{NH}_{3}$ volatilization in the field. J. of Prod. Agr. 1 (2):104111.

Hargrove, W. L., B. R. Bock, R. A. Raunikar, and W. J. Urban. 1987. Comparison of a forced-draft technique to nitrogen-15 recovery for measuring $\mathrm{NH}_{3}$ volatilization under field conditions. Soil Sci. Soc. Am. J. 51: 124-128. 
Harper, L. A. et al. 1983. Ammonia volatilization: soil, plant, and microclimate effects on diurnal and seasonal fluctuations. Agron. J. 75: 212-218.

Harper, L. A. et al . 1987. Nitrogen cycling in a wheat crop: soil, plant, and aerial nitrogen transport. Agron. J. 79:965-973.

Harper, L. A., V. R. Catchpoole, and I. Vallis. 1983. Gaseous $\mathrm{NH}_{3}$ transport in a cattlepasture system. In: Gaseous Loss of Nitrogen from Plant-Soil Systems. Freney, J. R. and J. R. Simpson (Eds.). Nijhoff Publ. Co. The Hague.

Hartman, Nile F. 1990. Optical sensing apparatus and method. U. S. Patent 4,940,328, July 10, 1990. Georgia Tech Research Institute. Atlanta, Georgia.

Hartman, N.F., D. P. Campbell, and M. Gross. 1988. Multimode waveguide chemical sensor. LEOS Annual Meeting-OPTCOM 88. Santa Clara, California.

Keeney, D. R. 1986. Nitrate in ground ${ }^{\circ}$ water - agricultural contribution and control. In: Proceedings of Agricultural Impacts on Ground Water - A Conference. National Water Well Association. Dublin, OH.

Kepner, R. A., R. Bainer, and E.L. Barger. 1978. Principies of Farm Machinerl Third Edition, AVI Publishing Company, Inc. Westport, CT.

Kogelnik, H. and H.P. Weber. 1974. Rays, stored energy, and power flow in dielectric waveguides. Journal of Optical Society of America 14 (2):174-185.

Lemon, E. R. and R. Van Houtte. 1980. Ammonia exchange at the land surface. Agron. J. 72:876-883.

Murday, J., S. Caras, and H. Wohltjen. 1987. Performance limits of chemical microsensor technology. Proceeding of the 1986 U. S. Army Chemical Research, Development and Engineering Center Scientific Conference on Chemical Defense Research, 18-21 November 1986, Vol 2.

Orofino, T. A., D. J.Dand, and E. E. Hardy. 1977. A technique for work-station monitoring utilizing optical waveguides. Presented at the Fourth Joint Conference on Sensing Environmental Pollutants. New Orleans, Louisiana.

Peseck et al. 1989. Alternative Agriculture. Committee on the Role of Alternative Farming Methods in Modern Production Agriculture. Board on Agriculture. National Research Council. National Acaderny Press. Washington, D.C.

Ross, C. C. 1987. Evaluation of an electrochemical sensor for monitoring atmospheric $\mathbf{N H}_{3}$ in animal housing. American Society of Agricultural Engineers. Paper 87-3056. St. Joseph, Michigan. 
Ross, C. C. and W. D. R. Daley. 1986. Ammonia sensing in broiler house environments. American Society of Agricultural Engineers. Paper 86-4044. St. Joseph, Michigan.

Shonk, J. L. and L. D. Gaultney. 1988. Spectroscopic sensing for the determination of organic matter content. American Society of Agricultural Engineers. Paper 88-2142. St. Joseph, MI.

Tiefenthaler, K., and W. Lukosz. 1984. Intergrated optical switches and gas sensors. Optics Letters. 10 (4).

Tien, P. K. 1971. Light waves in thin films and integrated optics. Applied Optics, 10 (11): 2395-2413.

Urban, W. J., W. L. Hargrove, B. R. Bock, and R. A. Raunikar. 1987. Evaluation of ureaurea phosphate as a nitrogen source for no-tillage production. Soil Sci. Soc. Am. J. 51:746:749.

Verber, C.M. 1984. Integrated-optical approaches to numerical optical processing. Proceedings of the IEEE. 72 (7).

Weast, R. C. (editor). 1985. CRC Handbook of Chemistry and Physics 65th Edition. CRC Press Inc. Boca Raton, FL.

Weier, K. L., V. R. Catchpoole, and L. A. Harper. 1980. An automated colorimetric method for the determination of small concentrations of ammonia in dilute acid solution. Tropical Agronomy Technical Memorandum Number 20. CSIRO. Division of Tropical Crops and Pastures. St. Lucia, Brisbane, Queensland, Australia.

Zemel, J. N. . 1986. Recent advances in chemically sensitive electronic devices. In: Fundamentals and Applications of Chemical Sensors. Ed. D. Schuetzle. American Chemical Society. Washington, D.C. 


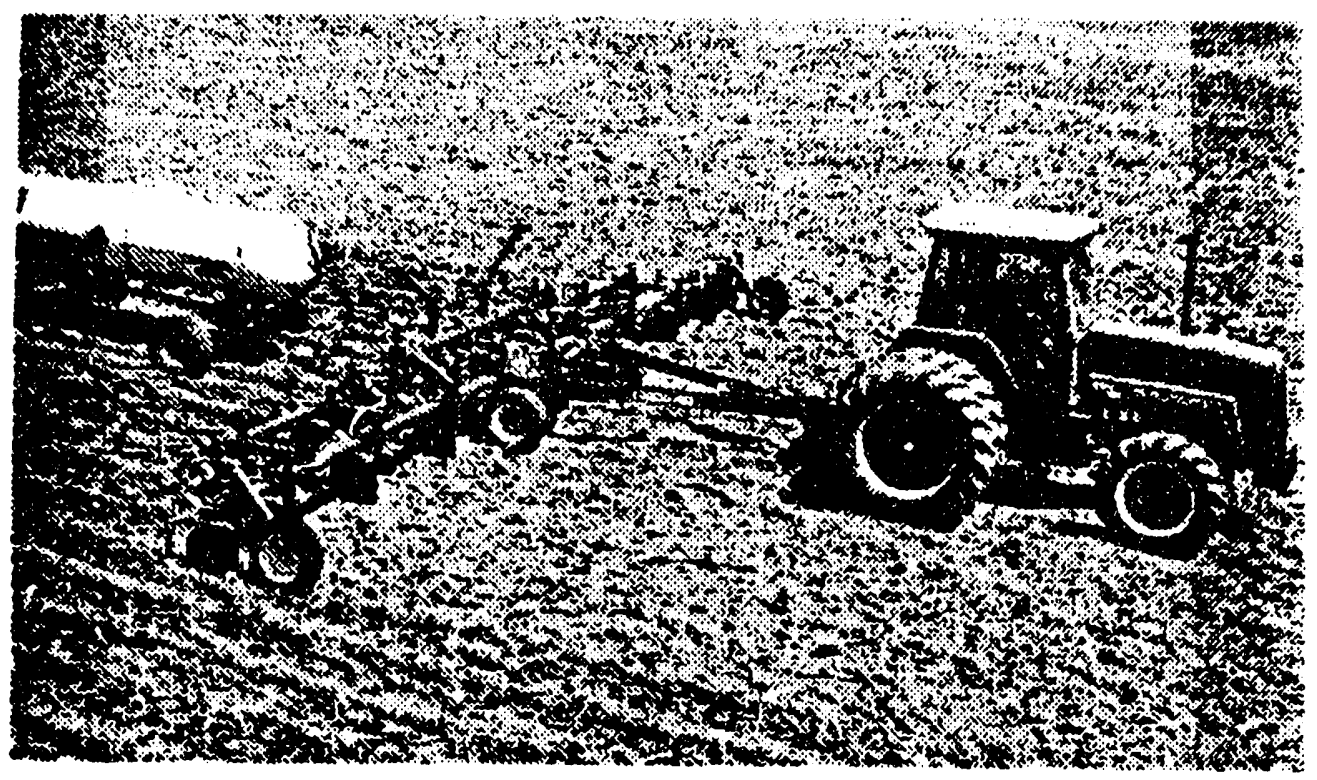

Figure 1. Anhydrous Ammonia Application During Field Operations

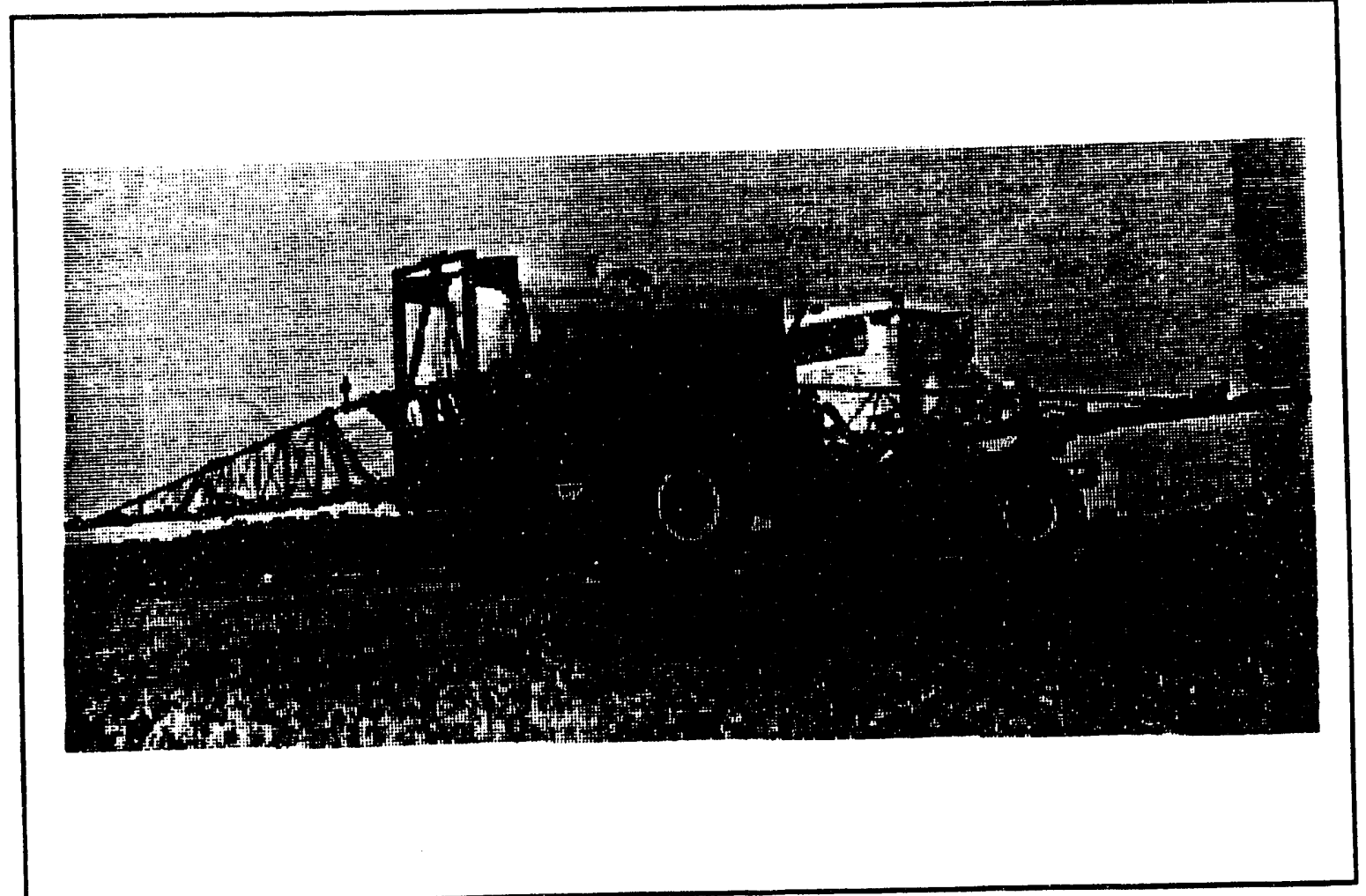

Figure 2. Liquid Fertilizer Applicator Rig 


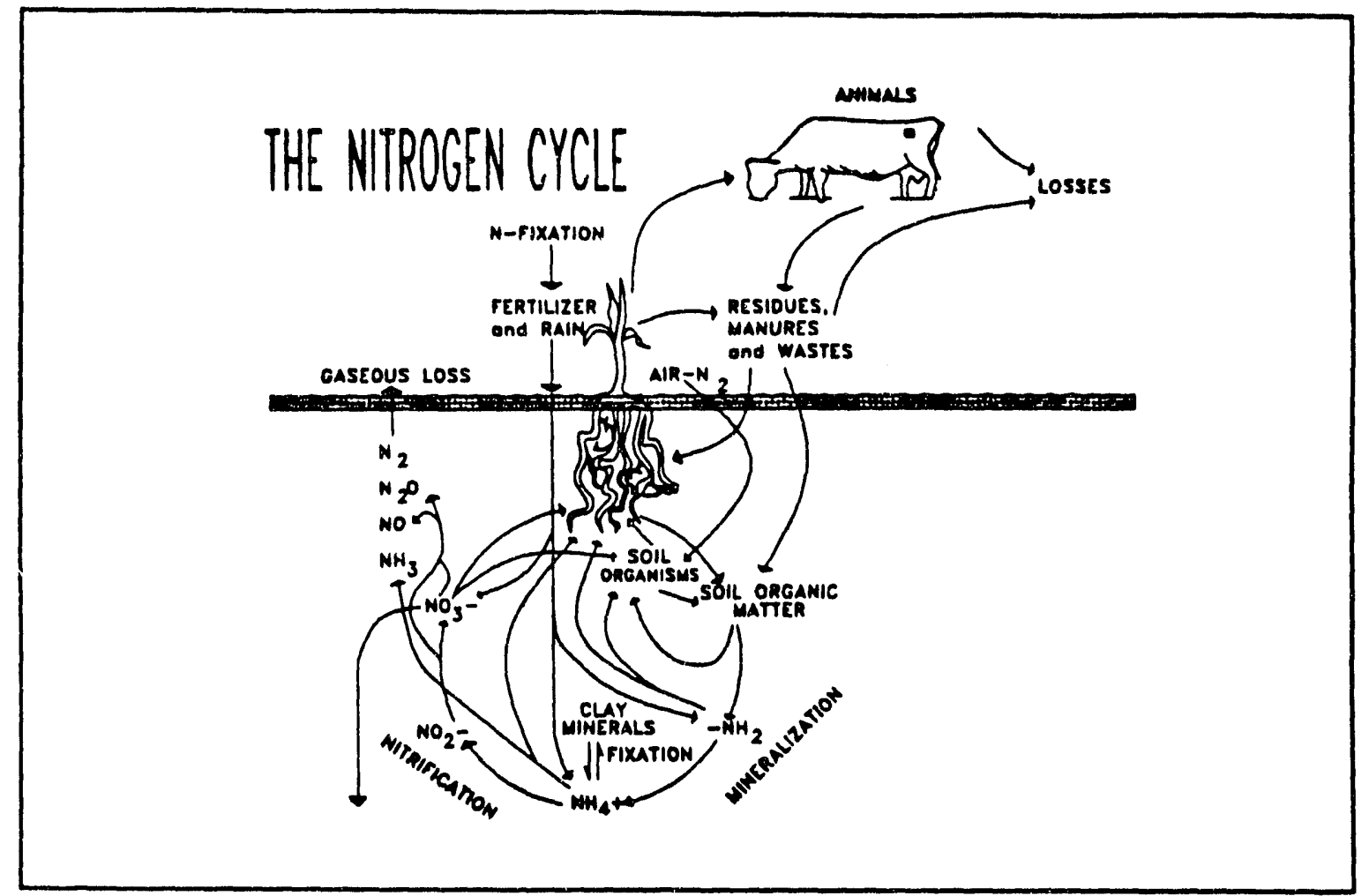

Figure 3. Nitrogen Cycle

\section{IO INTERFEROMETRIC CHEMICAL SENSOR}
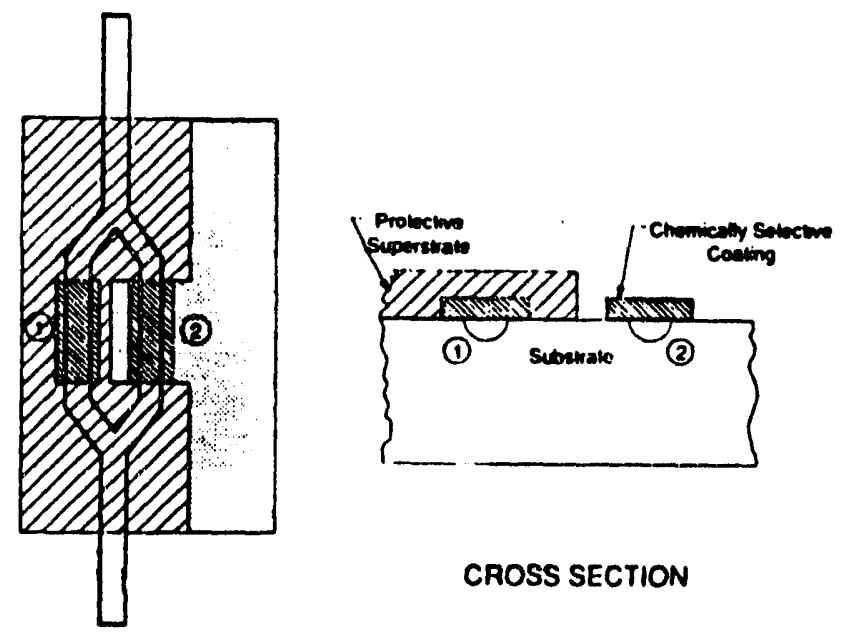

TOP VIEW

CROSS SECTION

Figure 4. Single Mode Mach-Zehnder Configuration 


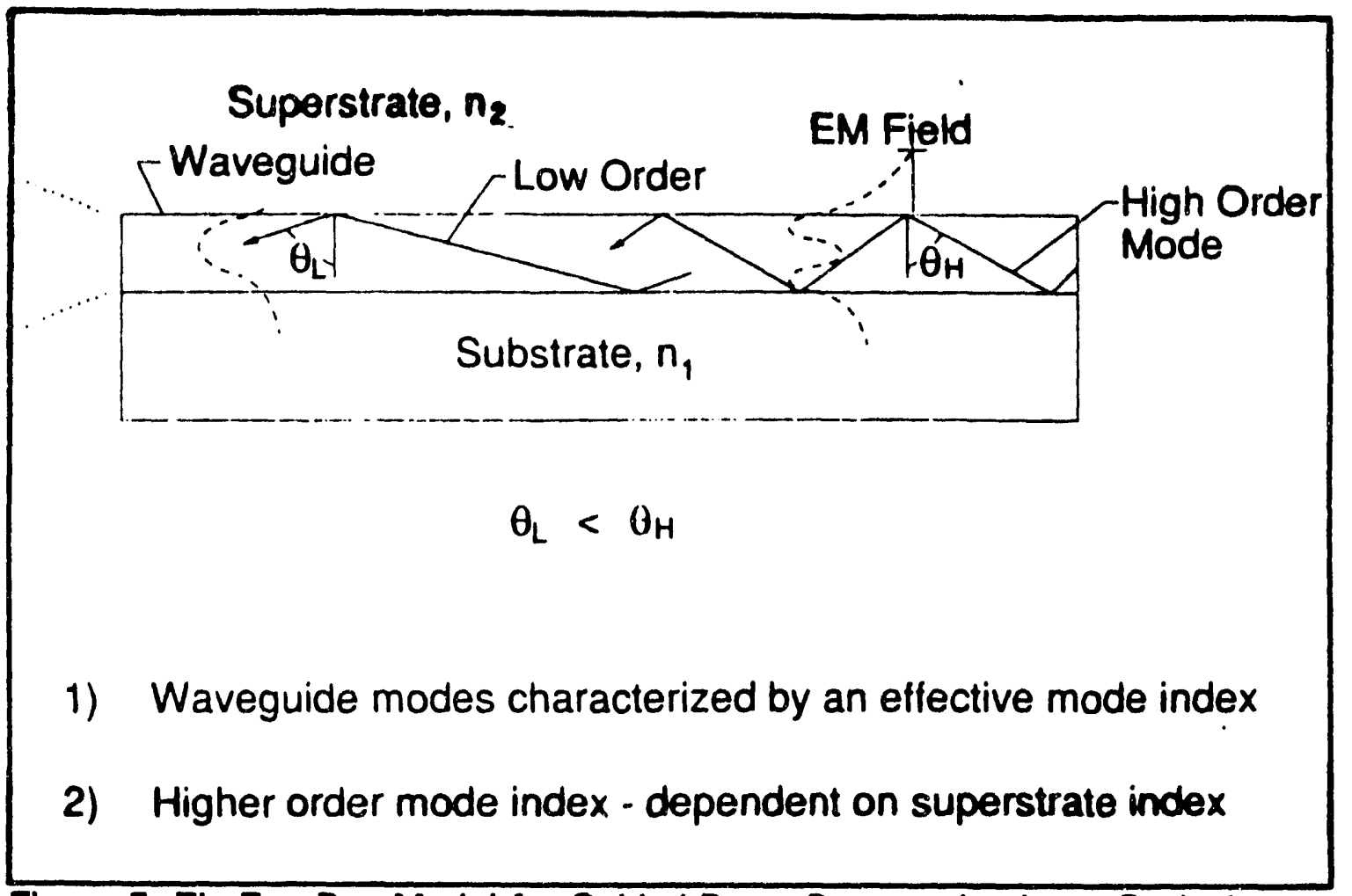

Figure 5. Zig-Zag Ray Model for Guided Beam Propagation in an Optical Waveguide

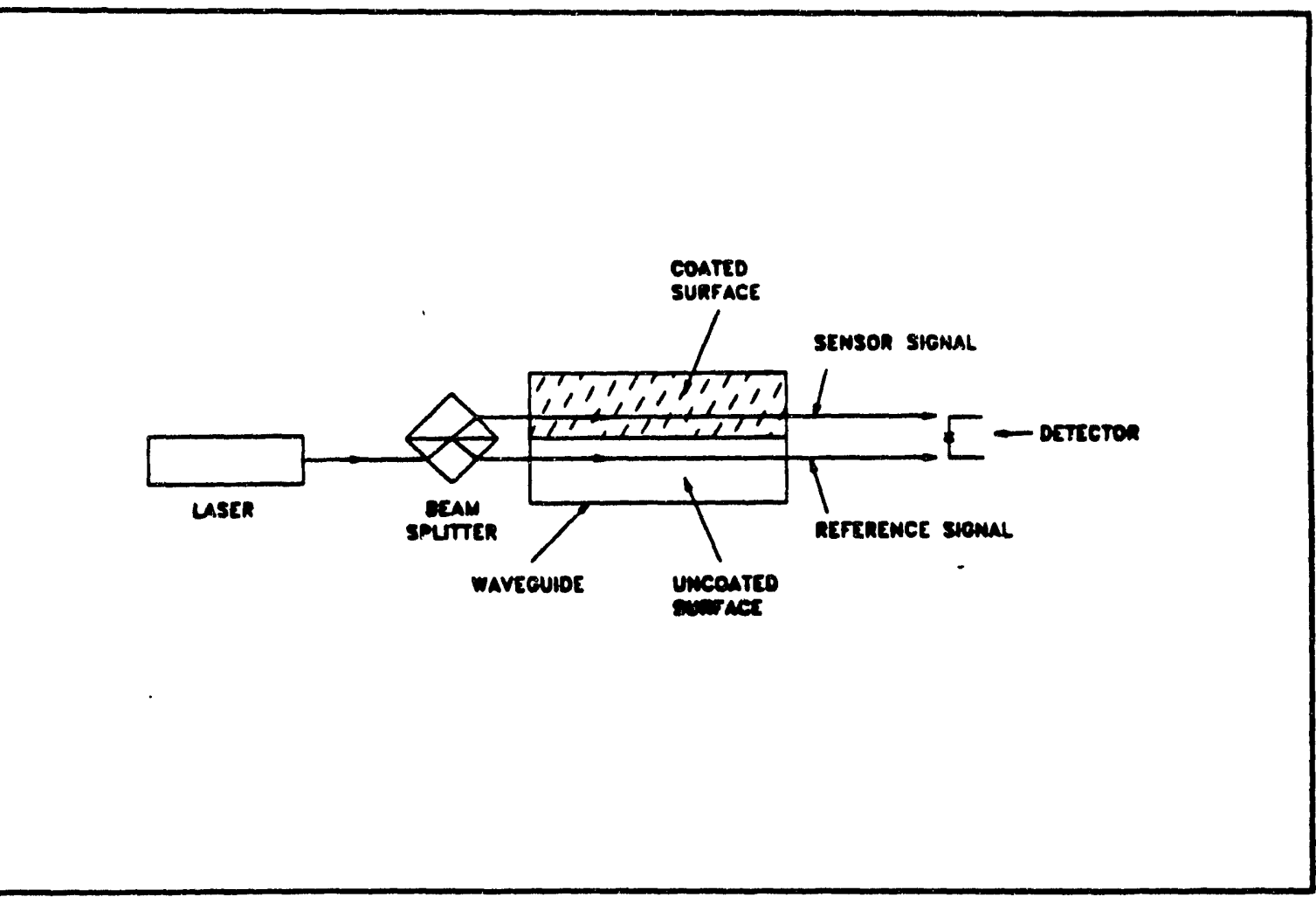

Figure 6. Experimental Setup for Absorption Device 


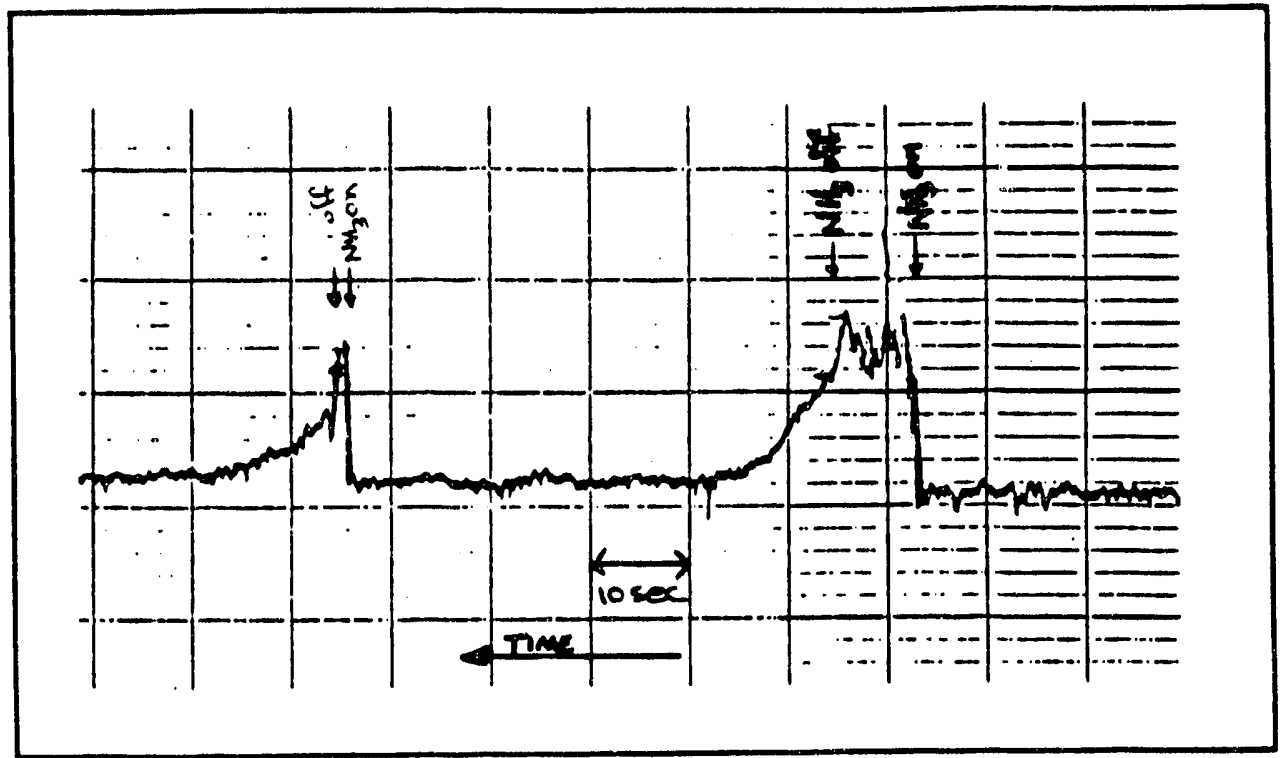

Figure 7. Response of Absorption Device to Ammonia 


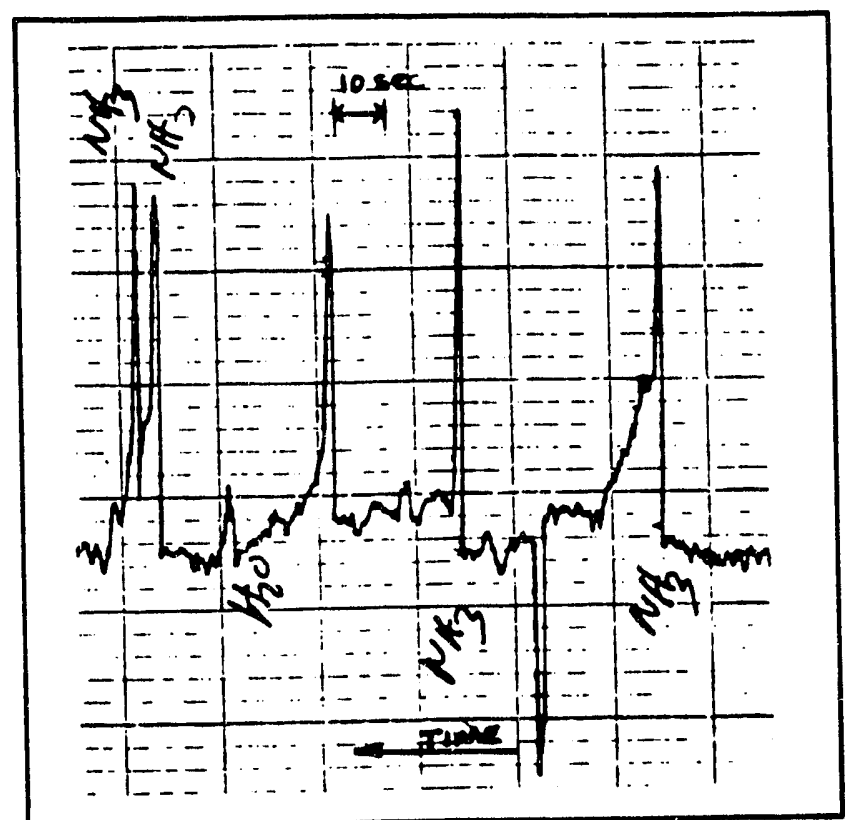

Figure 8. Response of Absorption Device to Ammonia and Humidified Air 


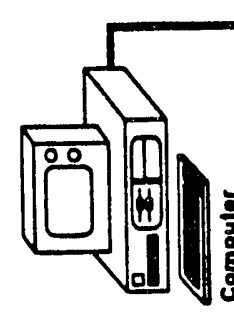

䇐

$\square$

iiI

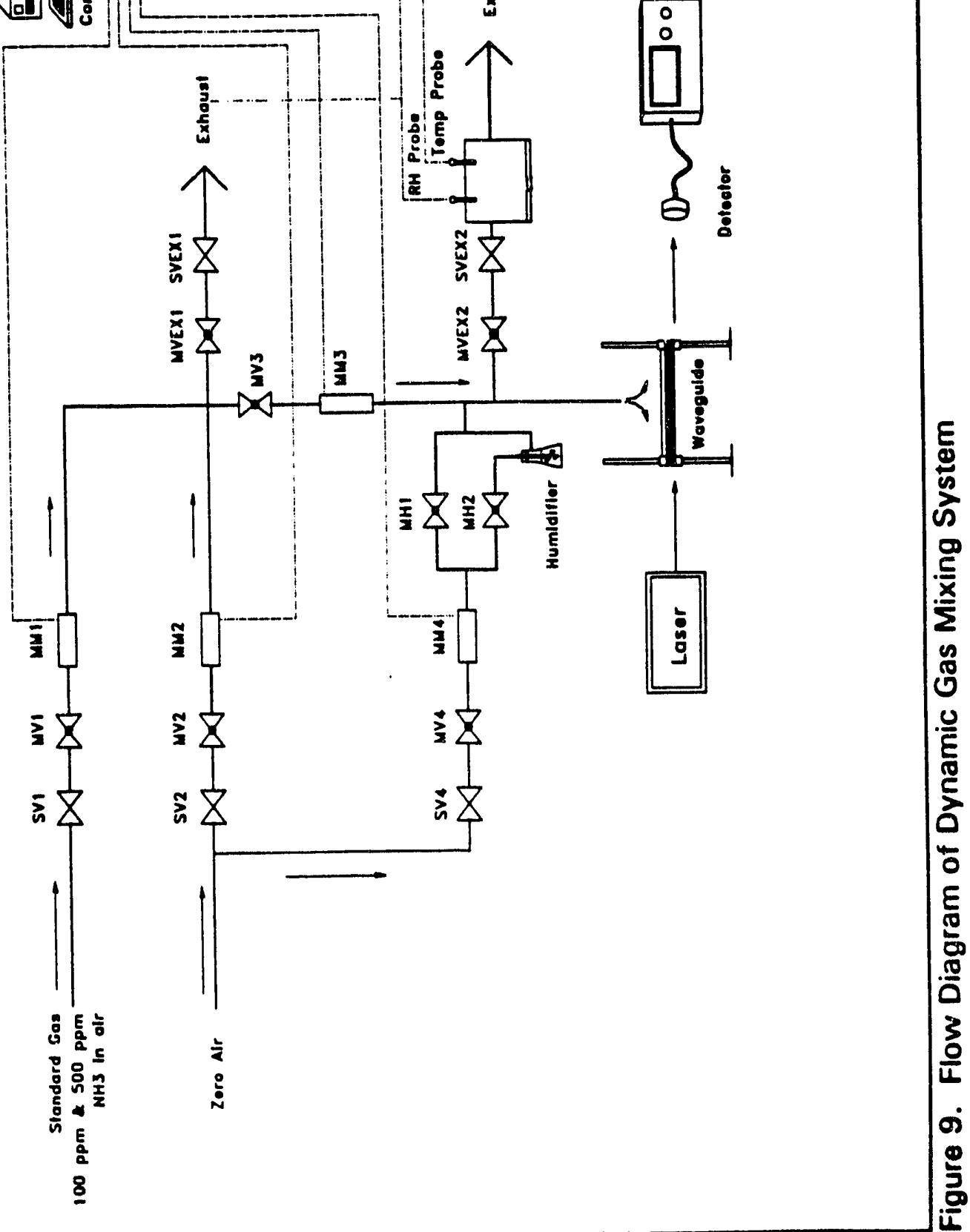




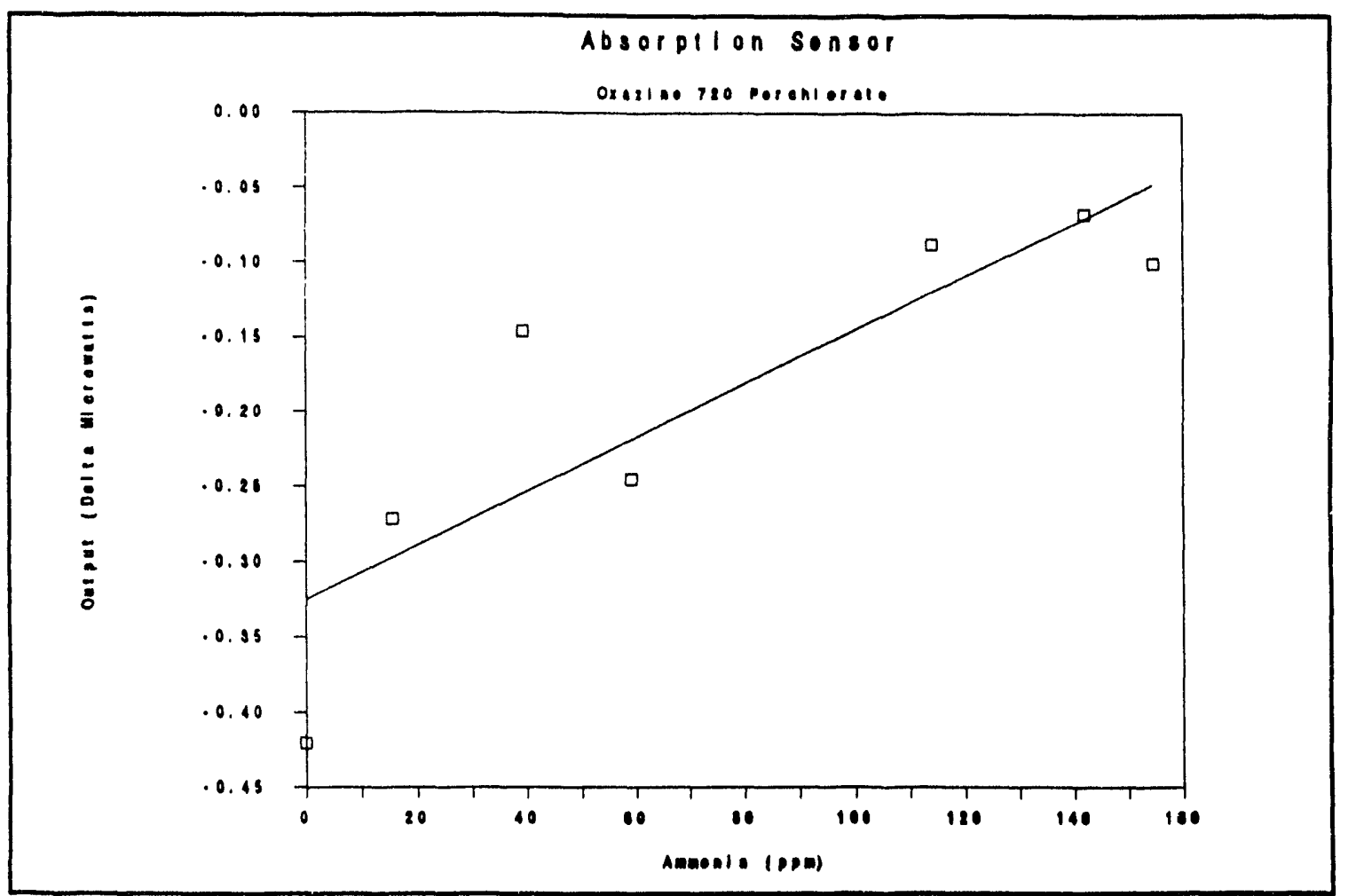

Figure 10. Average Response of Absorption Sensor to Varying Ammonia Concentration (Test 56-72)

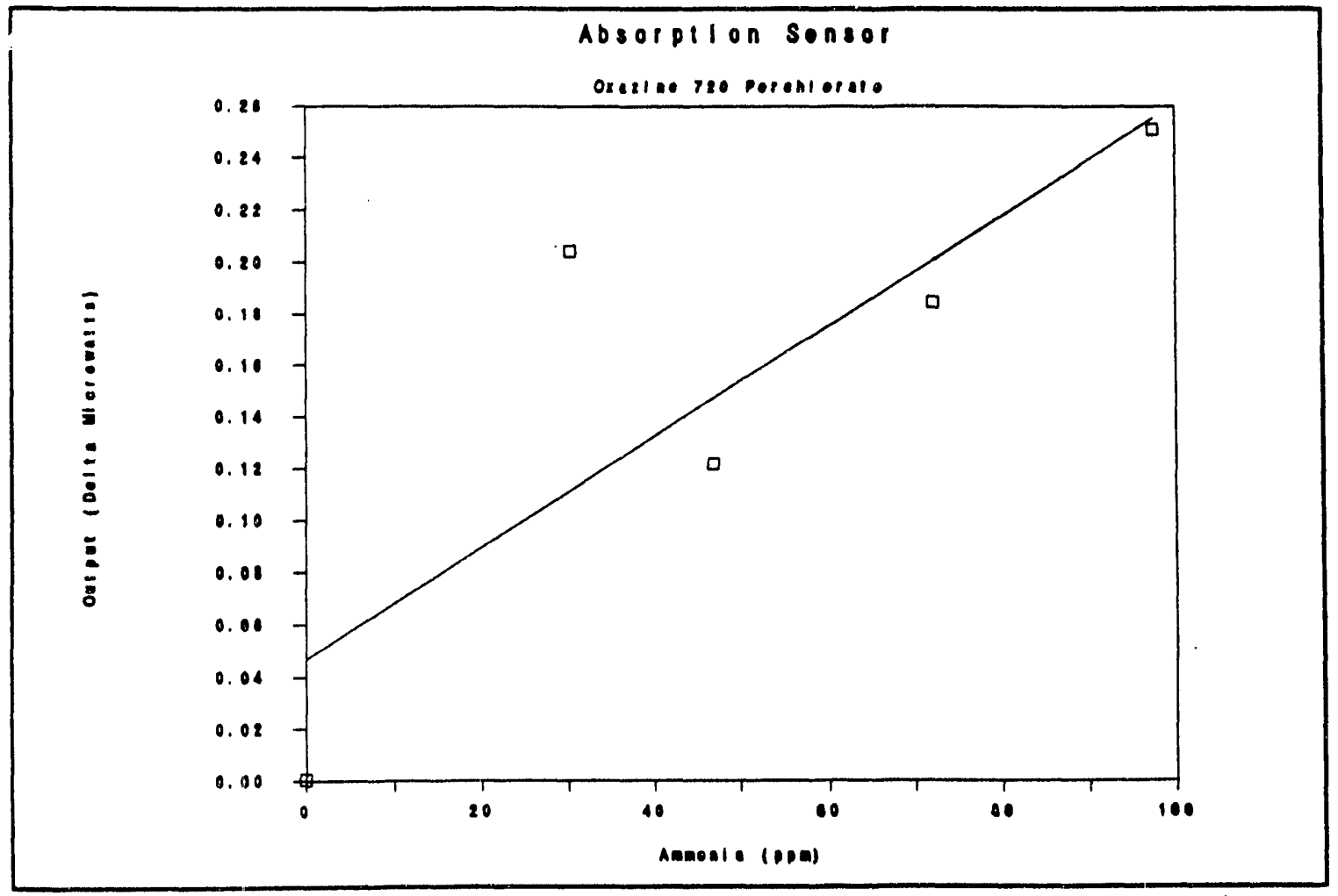

Figure 11. Average Response of Absorption Sensor to Varying Ammonia Concentration (Test 75-81) 


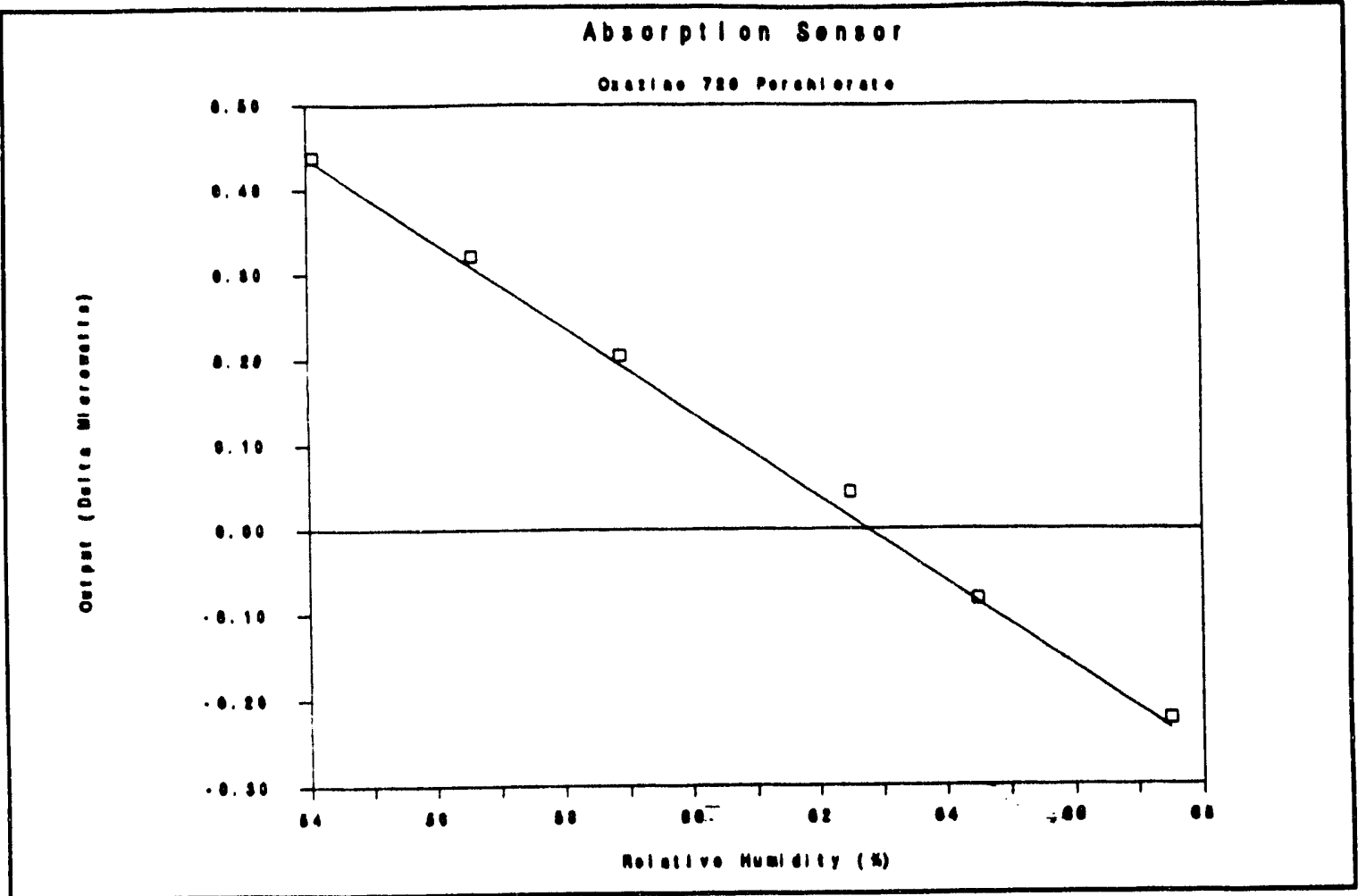

Figure 12. Average Response of Absorption Sensor to Varying Relative Humidity (Test $\mathbf{8 2 . 8 9}$ )

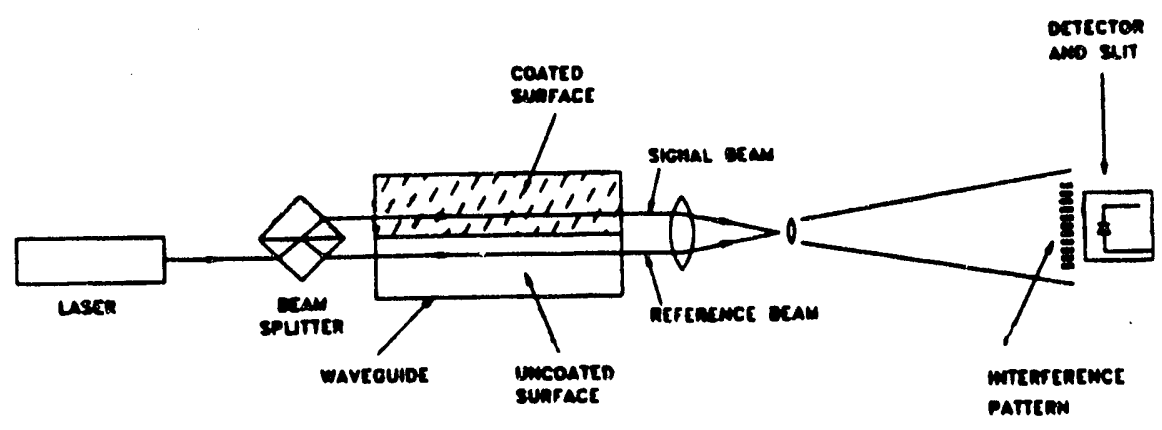

Figure 13. Experimental Setup for Interferometric Sensor 


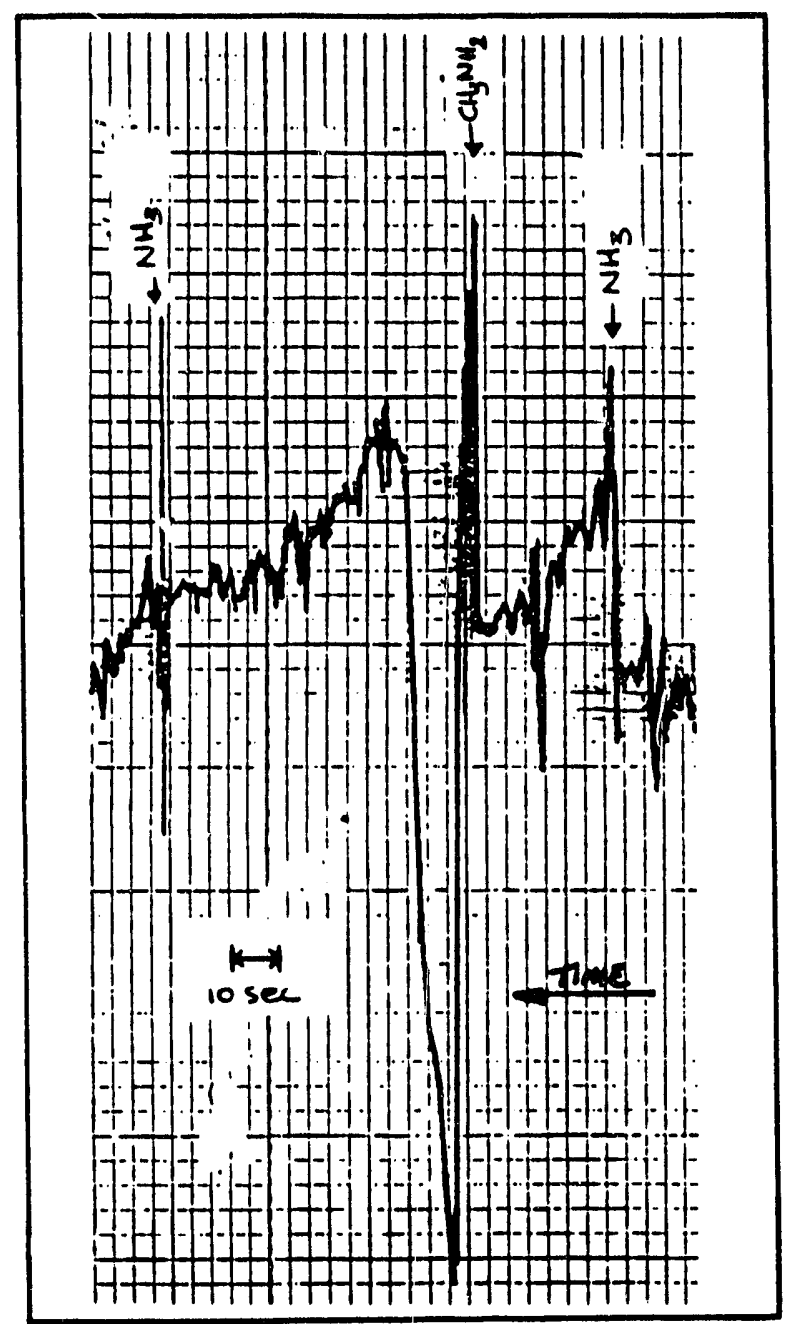

Figure 14. Responsi of Interferometric Sensor to Methylamine and Ammonia 


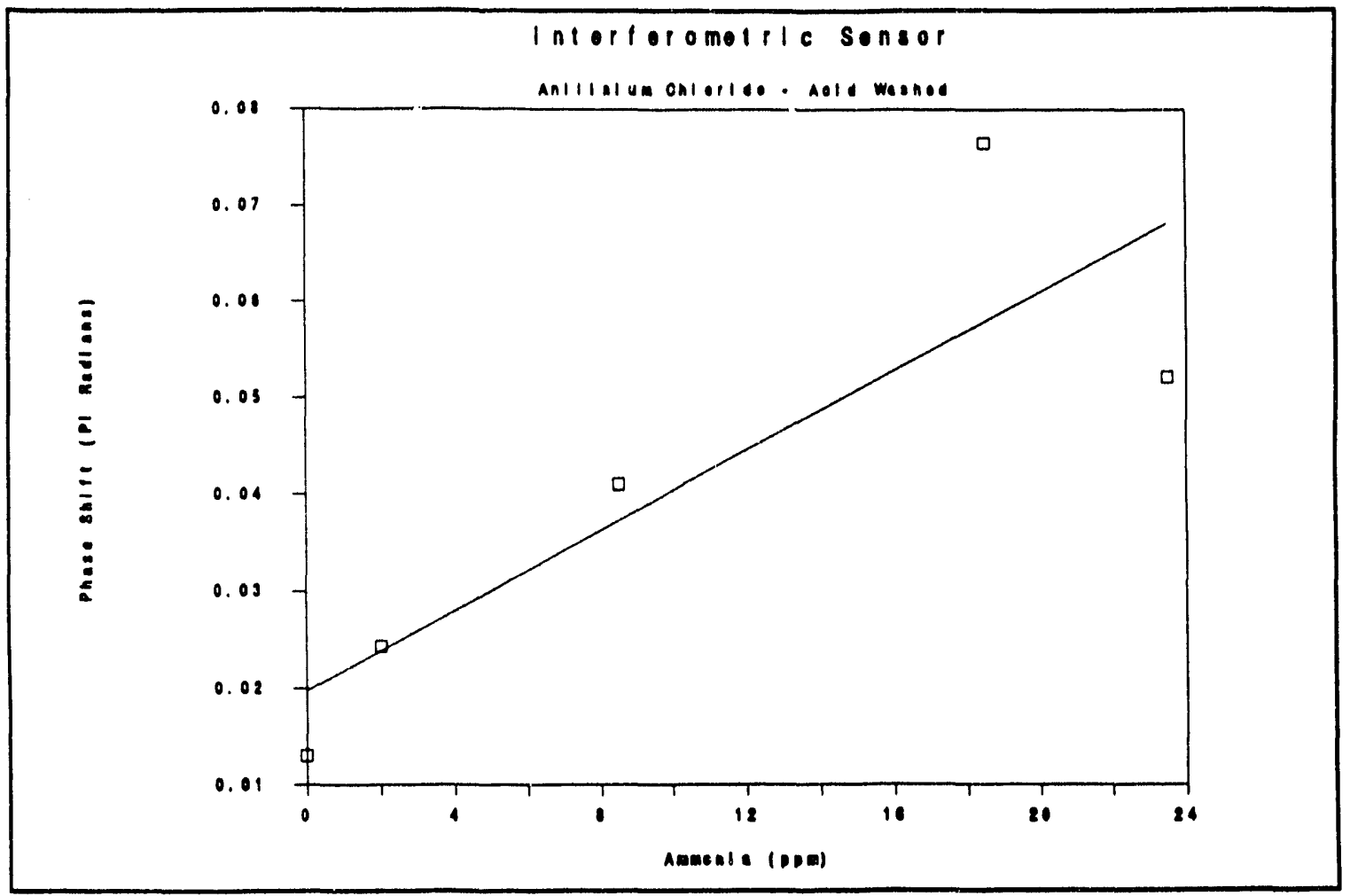

Figure 15. Average Response of Interferometric Sensor to Varying Ammonia Concentration (Test 98-101, 108, 109)

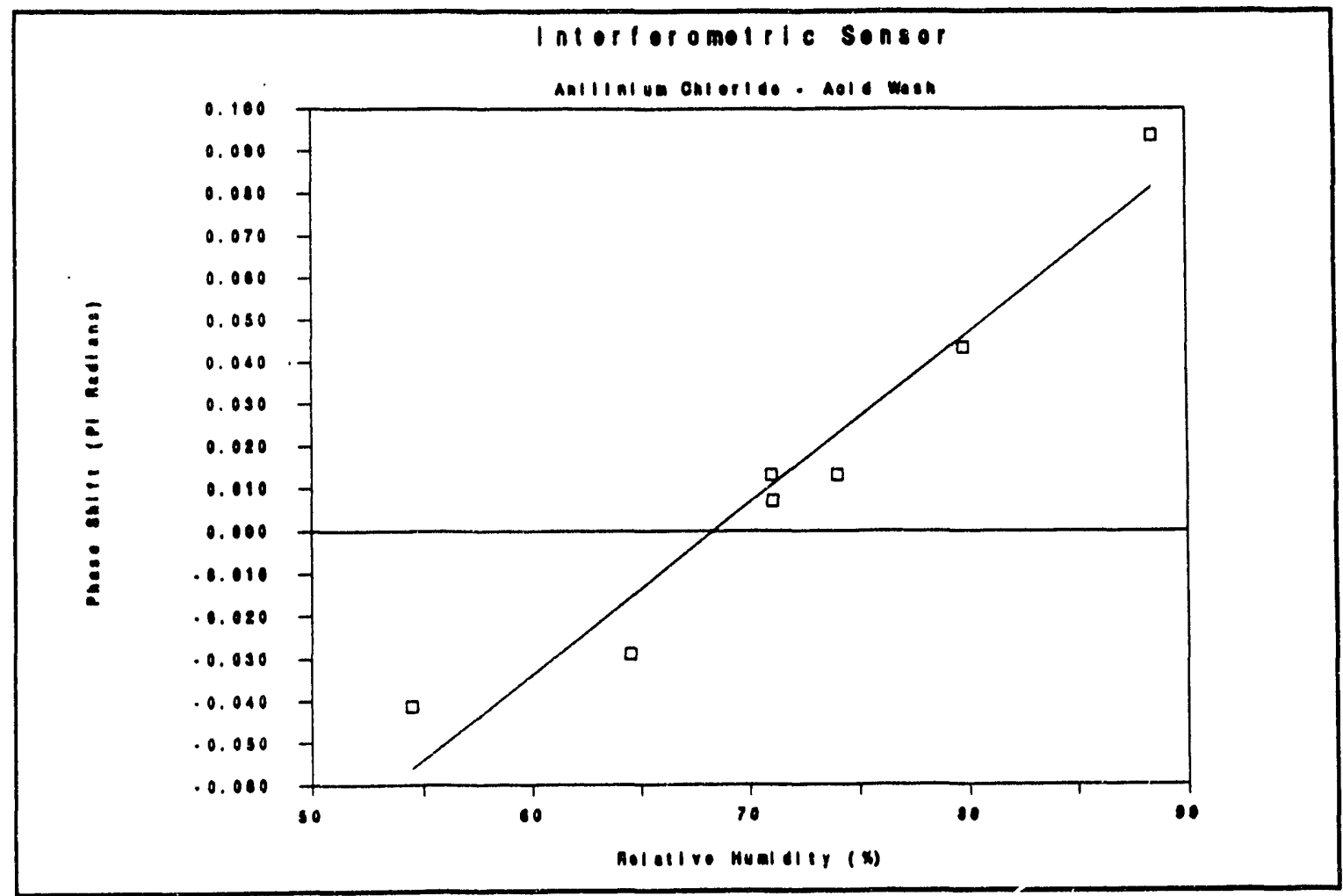

Figure 16. Average Response of Interferometric Sensor to Varying Relative Humidity (Test 102-107) 


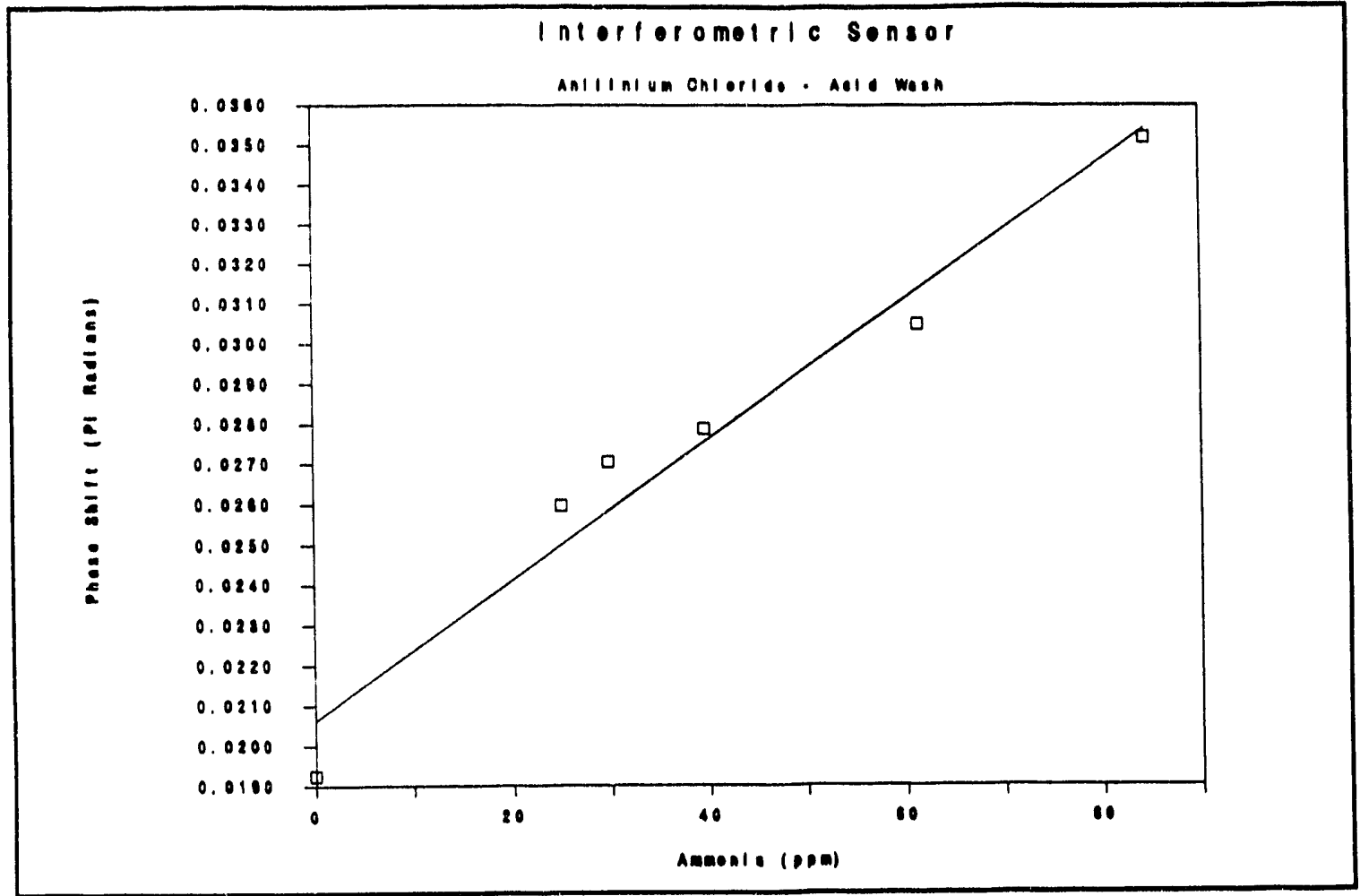

Figure 17. Average Response of Interferometric Sensor to Varying Ammonia Concentration (Test 128-133)

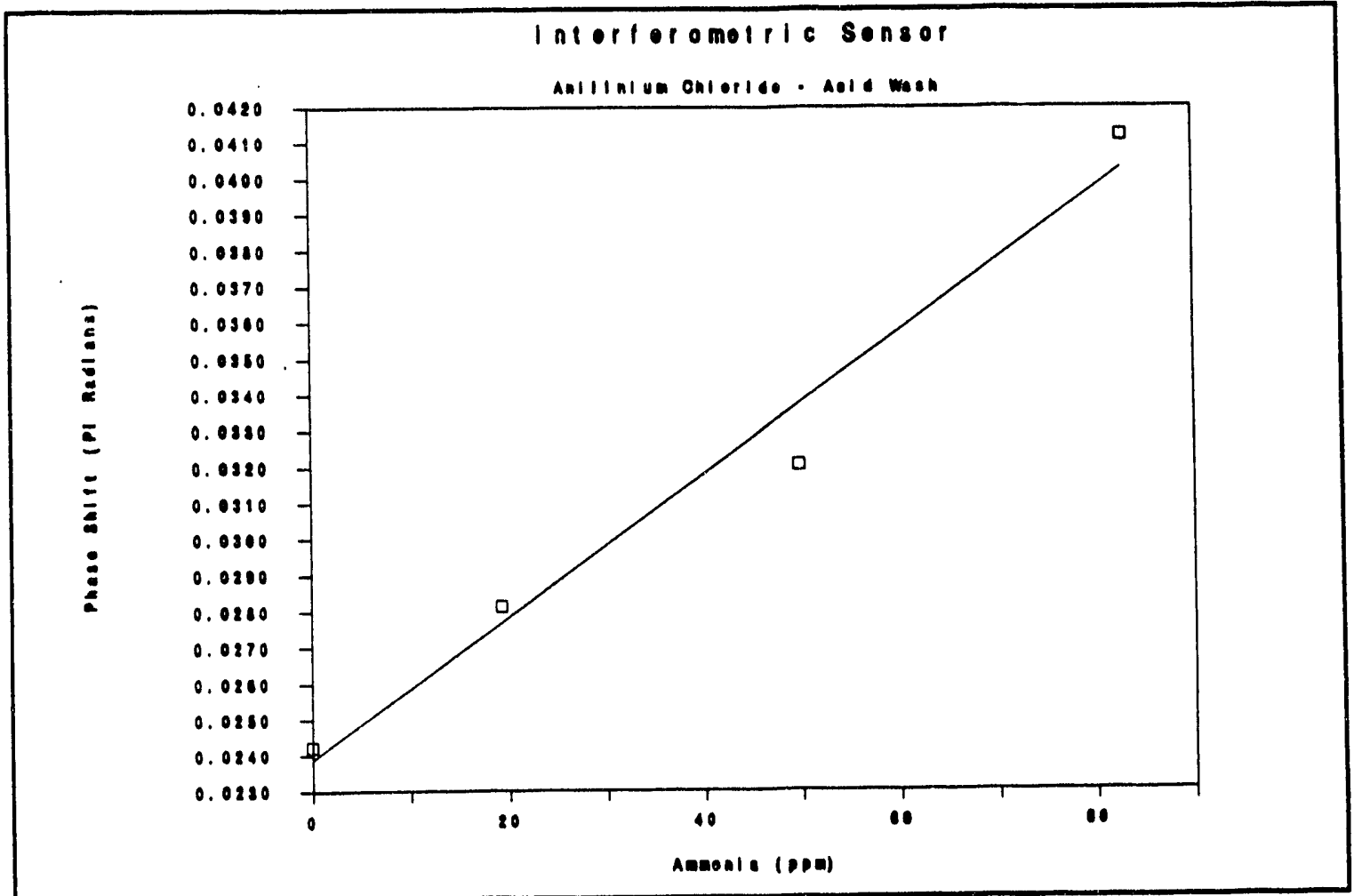

Figure 18. Average Response of Interferometric Sensor to Varying Ammonia Concentration (Test 134-137) 


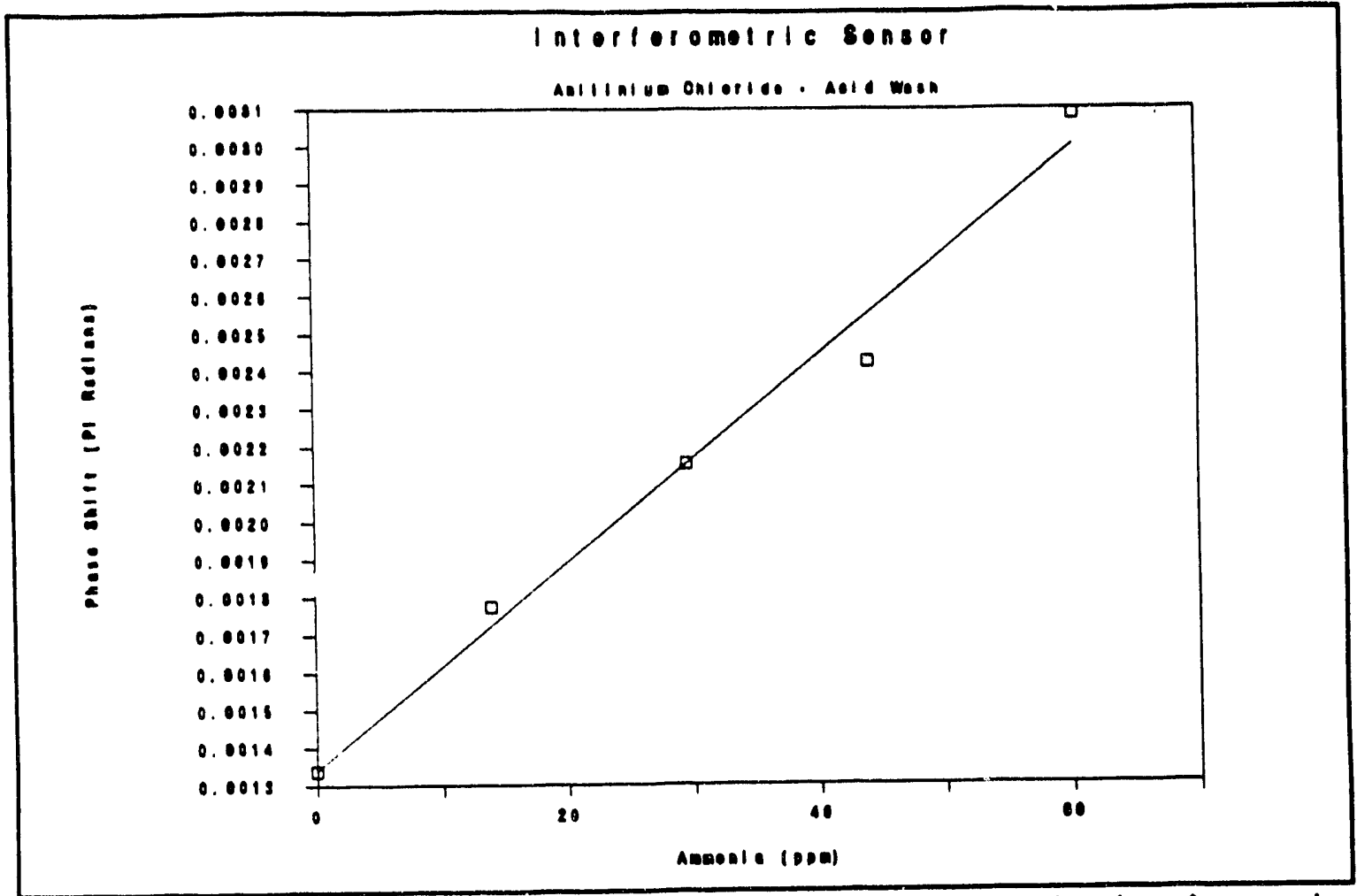

Figure 19. Average Response of Interferometric Sensor to Varying Ammonia Concentration (Test 138-148)

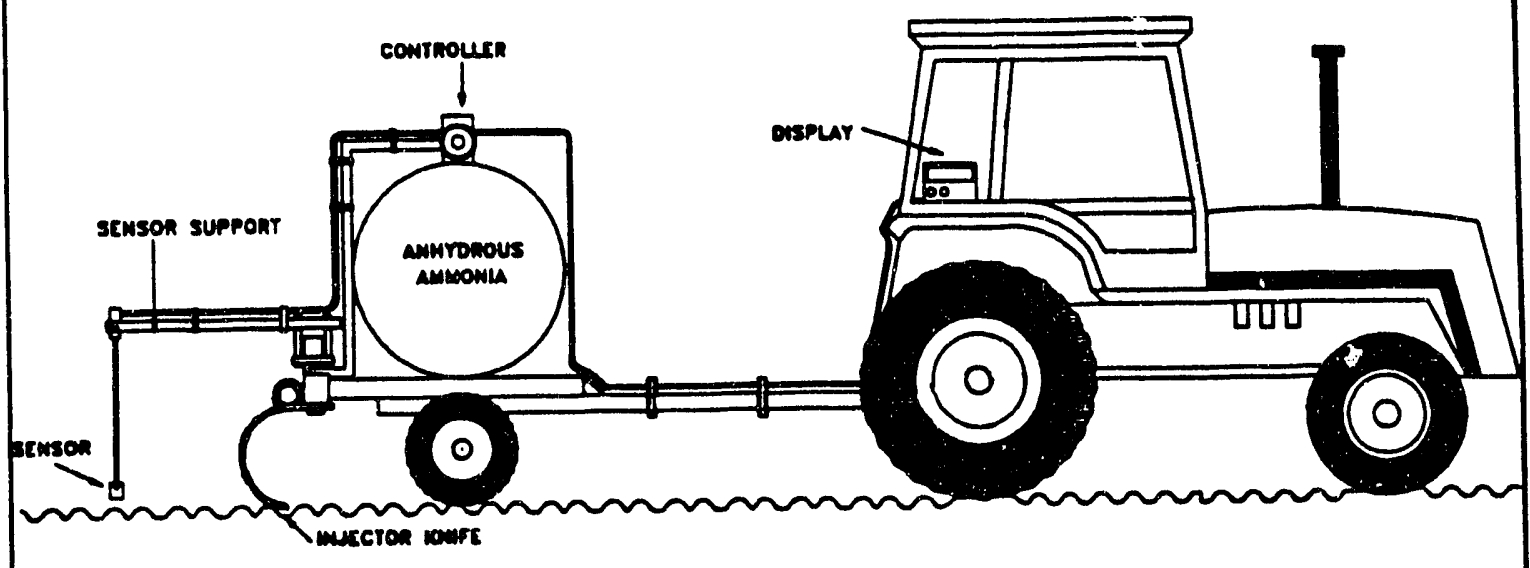

Figure 20. Conceptual Drawing of Post-Application Ammonia Monitoring System 


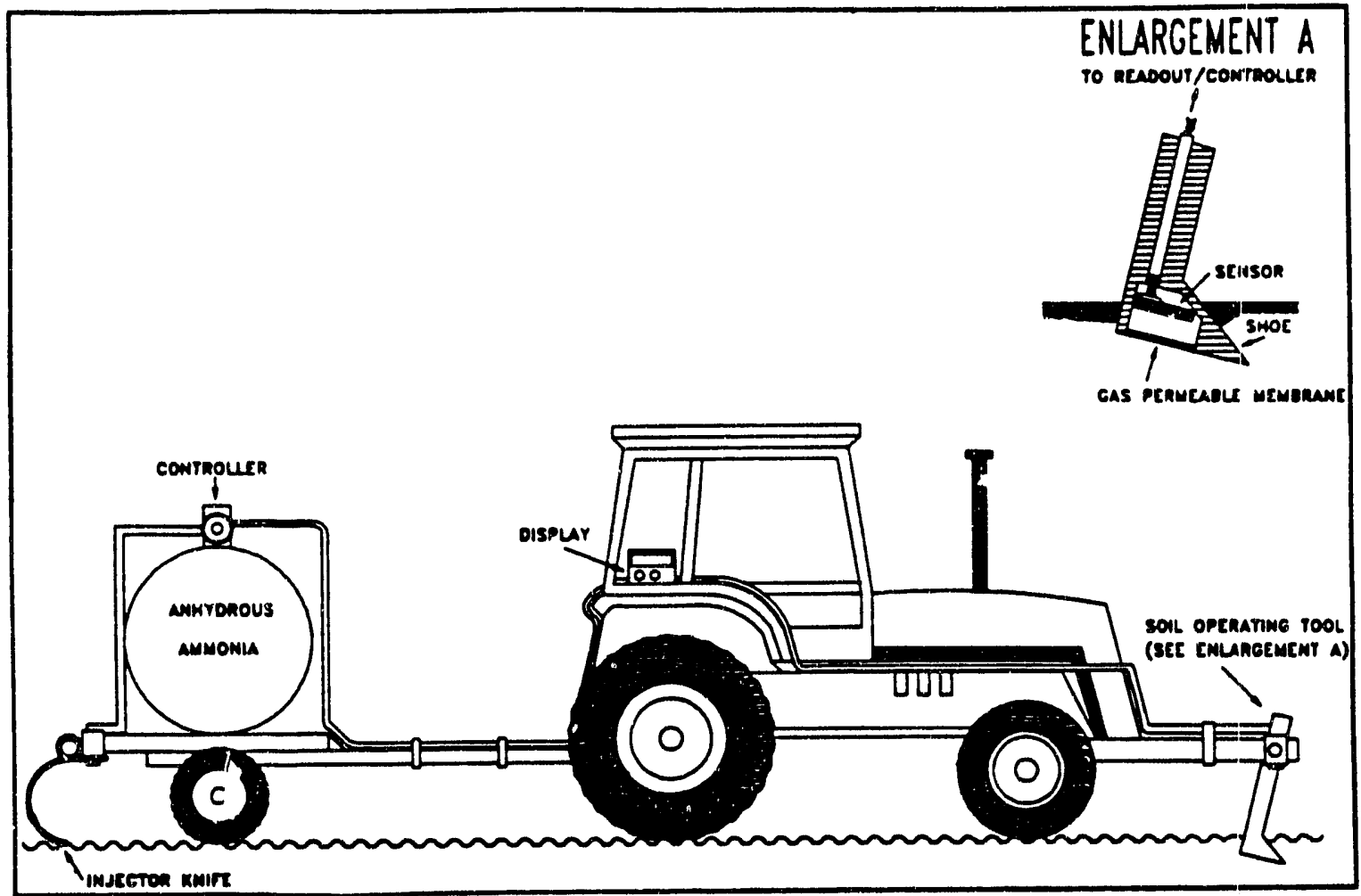

Figure 21. Conceptual Drawing of Pre-Application Ammonia Monitoring System

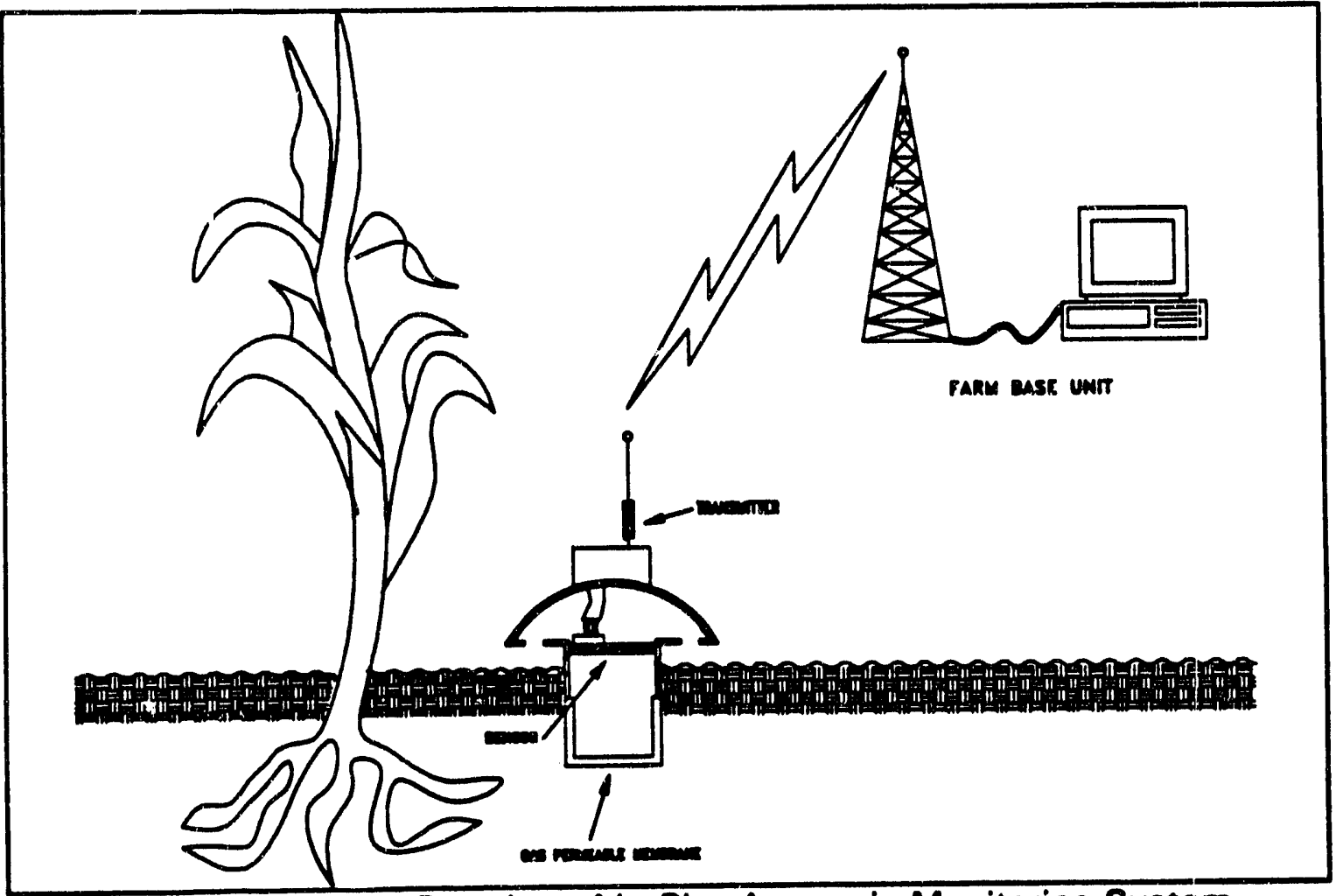

Figure 22. Conceptual Drawing of In-Situ Ammonia Monitoring System 


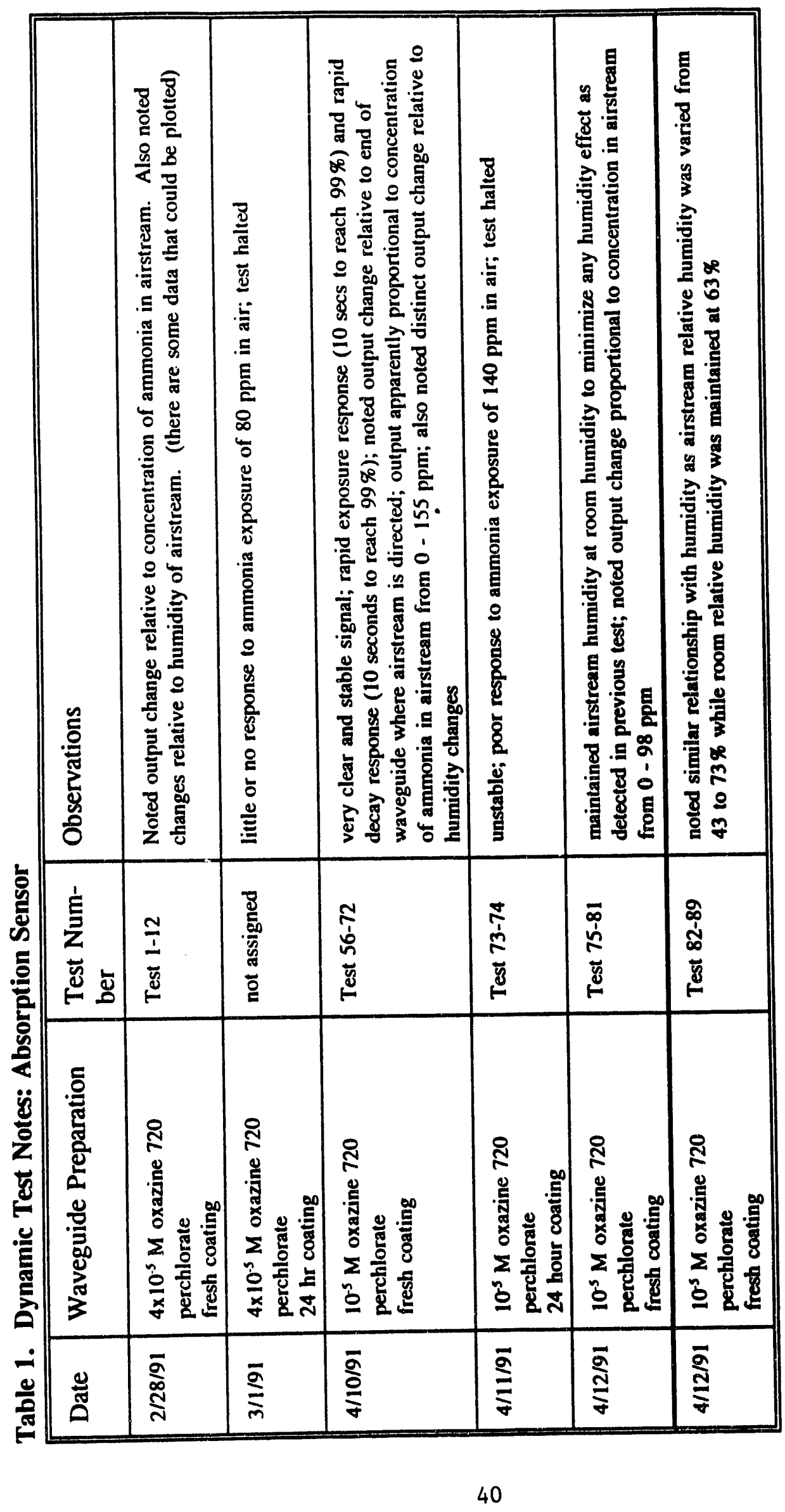




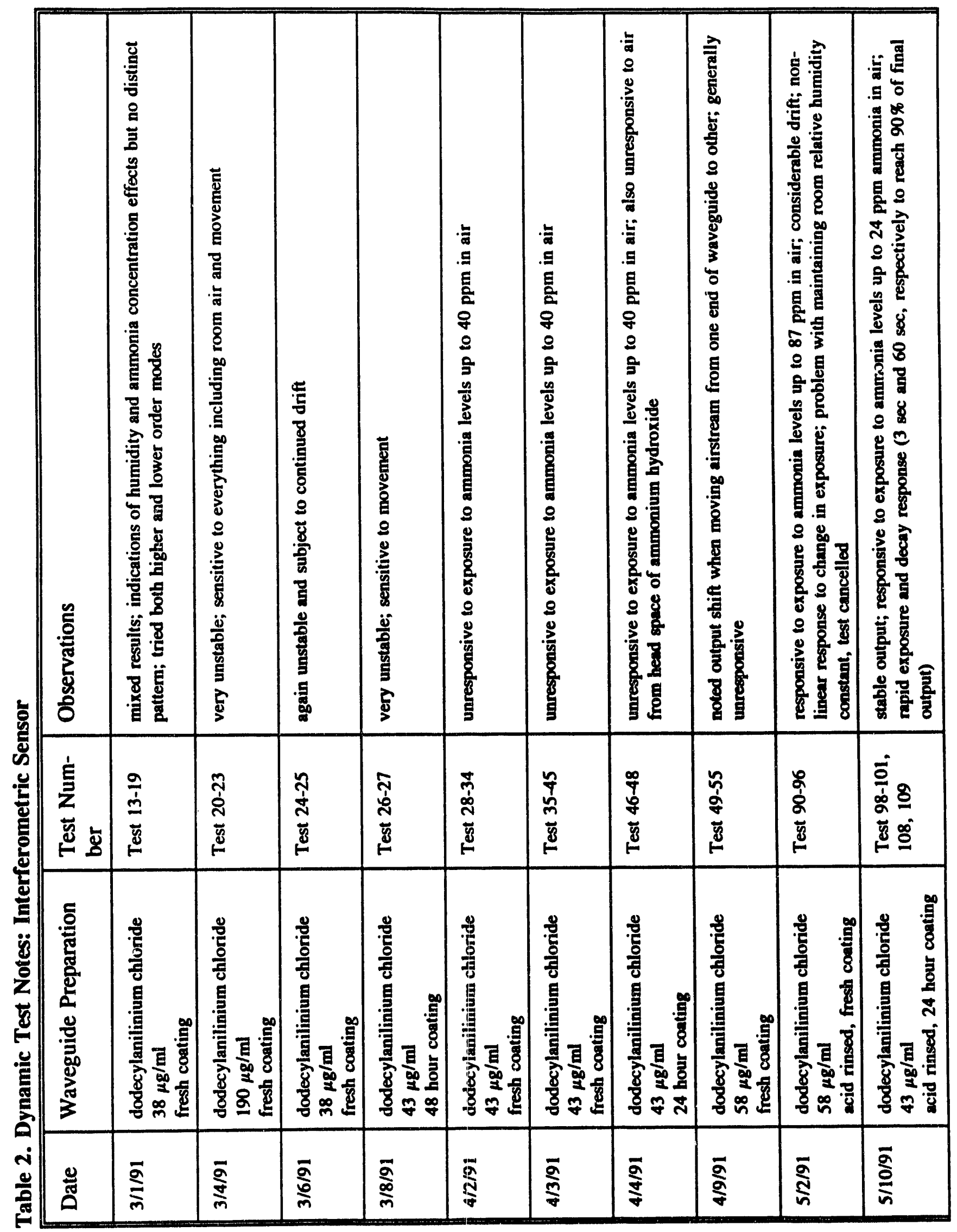




\begin{tabular}{|c|c|c|c|c|c|c|}
\hline 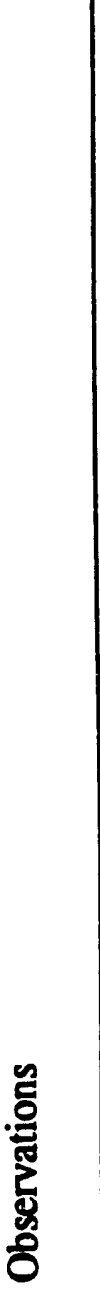 & 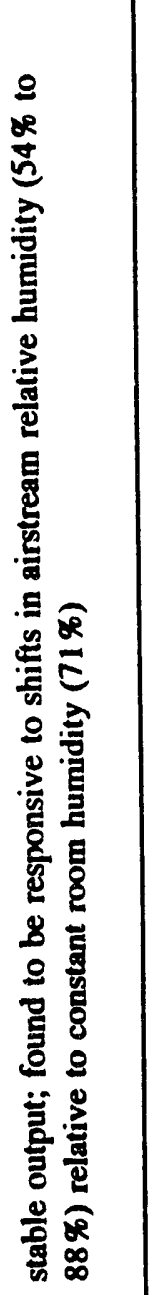 & 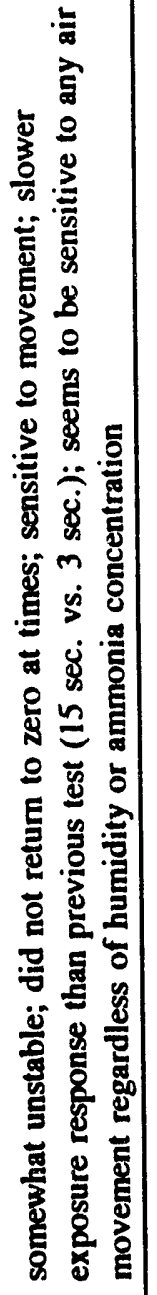 & 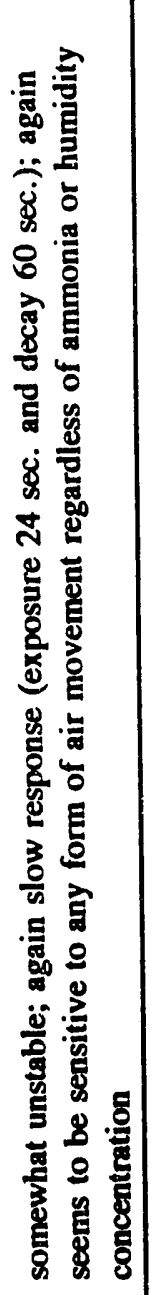 & 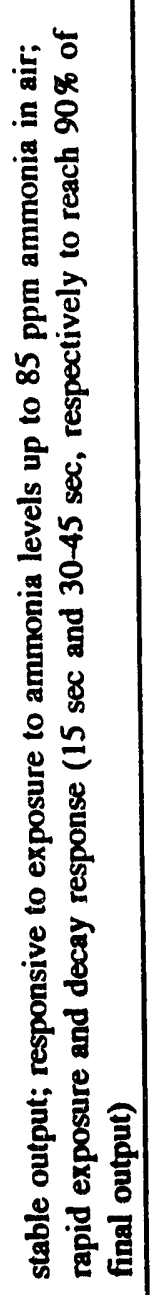 & 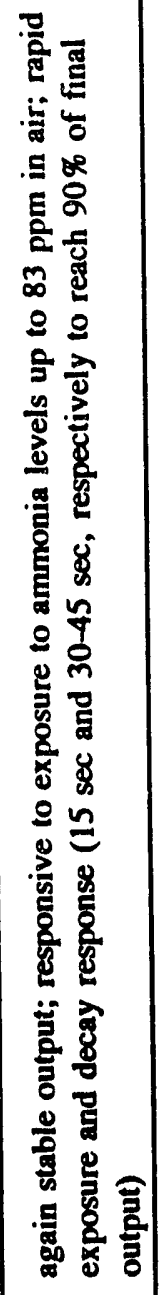 & 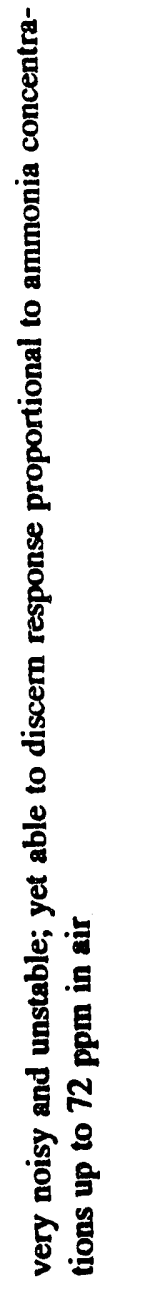 \\
\hline 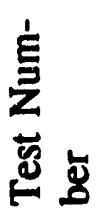 & $\frac{\frac{\delta}{\vdots}}{\frac{\delta}{\delta}}$ & 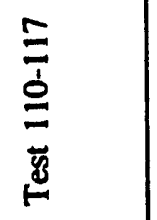 & 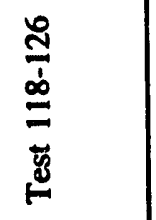 & 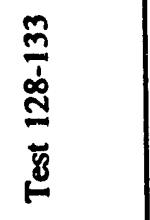 & $\frac{\bar{m}}{\frac{5}{m}}$ & 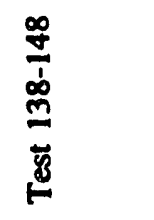 \\
\hline 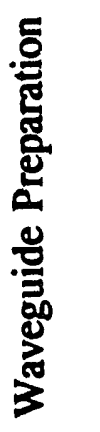 & 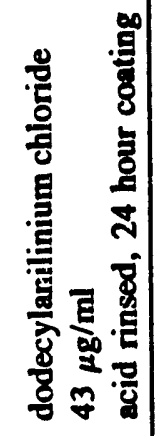 & 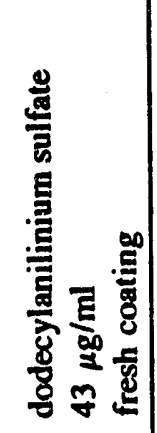 & 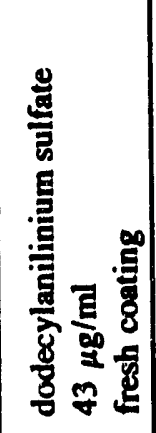 & 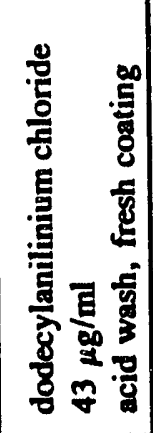 & 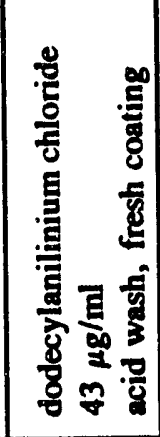 & 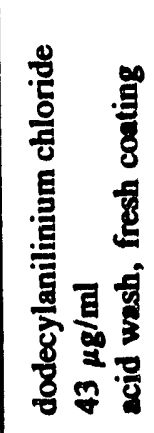 \\
\hline$\frac{\mathscr{U}}{\stackrel{0}{\circ}}$ & $\stackrel{\bar{a}}{\frac{\bar{a}}{\omega}}$ & $\frac{\bar{a}}{\frac{a}{n}}$ & $\frac{\bar{a}}{6}$ & $\underset{\infty}{\bar{\infty}}$ & $\underset{\infty}{\bar{a}}$ & $\underset{\infty}{\bar{a}}$ \\
\hline
\end{tabular}




\begin{tabular}{|c|c|c|c|c|c|c|c|}
\hline Fertilizer & $\begin{array}{r}\text { Total } \\
\text { Production } \\
\text { (thousand } \\
\text { tons) }\end{array}$ & $\begin{array}{r}\text { Percent } \\
\text { of } \\
\text { Total }\end{array}$ & $\begin{array}{r}\text { Selling } \\
\text { Price } \\
\text { (\$/ton) }\end{array}$ & $\begin{array}{r}\text { Selling } \\
\text { Price } \\
\text { (billion } \\
\$ \text { ) }\end{array}$ & $\begin{array}{r}\text { Energy for } \\
\text { Production } \\
\text { (million } \\
\text { Btu/ton) }\end{array}$ & $\begin{array}{r}\text { Total } \\
\text { Energy } \\
\text { for } \\
\text { Produc- } \\
\text { tion } \\
\text { (trillion } \\
\text { Btu) }\end{array}$ & $\begin{array}{r}\text { Total } \\
\text { Energy } \\
\text { for } \\
\text { Produc- } \\
\text { tion } \\
\text { (quads) }\end{array}$ \\
\hline Anhydrous Ammonia & 14,167 & $60.6 \%$ & $\$ 145$ & 2.05 & 40.34 & 571.50 & 0.572 \\
\hline Ammonium Nitrate & 2,579 & $11.0 \%$ & $\$ 126$ & 0.32 & 20.99 & 54.13 & 0.054 \\
\hline Ammonium Sulfate & 2,395 & $10.2 \%$ & $\$ 98$ & 0.23 & 10.84 & 25.96 & 0.026 \\
\hline Urea & 4,231 & $18.1 \%$ & $\$ 135$ & 0.57 & 30.10 & 127.37 & 0.127 \\
\hline Total & 23,372 & & & 3.19 & & 778.96 & 0.779 \\
\hline
\end{tabular}




\begin{tabular}{||l|r|}
\hline \multicolumn{2}{|l|}{ TABLE 4. INTEGRATED OPTICS SENSOR } \\
COST ESTIMATE & COST \\
\hline ITEM & $\$ 25$ \\
\hline Diode Laser & 5 \\
\hline Waveguide Substrate & 10 \\
\hline Detector Electronics & 10 \\
\hline Fiber/GRIN Lens & 10 \\
\hline Packaging Materials & 60 \\
\hline Fabrication Labor & 30 \\
\hline Profit & $\$ 150$ \\
\hline Total & \\
\hline
\end{tabular}




\begin{tabular}{||l|r|r||}
\hline \multicolumn{2}{||l|}{ TABLE 5. EVALUATION OF ENERGY SAVINGS AND ECONOMICS FOR MOBILE SENSOR } \\
\hline & $10.0 \%$ & \\
\hline Estimated Fertilizer Savings & & \\
\hline & 14,167 & thousand tons \\
\hline Total Anhydrous Ammonia Production & 2.05 & billion dollars \\
\hline Total Anhydrous Ammonia Selling Price & 0.21 & billion dollars \\
\hline Total Anhydrous Ammonia Production Purchase Savings & 0.572 & QUADS \\
\hline Total Anhydrous Ammonia Production Energy & 0.057 & QUADS \\
\hline Total Anhydrous Ammonia Production Energy Savings & & \\
\hline & & \\
\hline & 440 & Acres \\
\hline Average Farm Size in United States & 180 & pounds of nitrogen per \\
\hline Average Annual Fertilizer Application Rate & $82.4 \%$ & \\
\hline Nitrogen Content of Anhydrous Ammonia & 219 & pounds per acre \\
\hline Average Annual Anhydrous Ammonia Application Rate & 96,171 & pounds \\
\hline Total Fertilizer Applied & 48.09 & tons \\
\hline Total Fertilizer Applied & 4.81 & tons \\
\hline Total Fertilizer Savings & $\$ 697$ & per year \\
\hline Total Fertilizer Savings & $\$ 500$ & per unit \\
\hline Cost of Sensor & 0.72 & years \\
\hline Simple Payback & $139.4 \%$ & \\
\hline Return on Investment & & \\
\hline & & \\
\hline
\end{tabular}




\begin{tabular}{|c|c|c|}
\hline Estimated Fertilizer Savings & $10.0 \%$ & \\
\hline Total Solid Fertilizer Production & 9,205 & thousand tons \\
\hline Total Solid N Fertilizer Selling Price & 1.13 & billion dollars \\
\hline Total Solid N Fertilizer Production Purchase Savings & 0.11 & billion dollars \\
\hline Total Solid N Fertilizer Production Energy & 0.207 & QUADS \\
\hline Total Solid N Fertilizer Production Energy Savings & 0.021 & QUADS \\
\hline Average Farm Size in United States & 440 & Acres \\
\hline Average Annual Fertilizer Application Rate & 180 & $\begin{array}{l}\text { pounds of nitrogen per } \\
\text { acre }\end{array}$ \\
\hline Nitrogen Content of Ammonium Nitrate & $35.0 \%$ & \\
\hline $\begin{array}{l}\text { Average Annual Ammonium Nitrate Fertilizer Application } \\
\text { Rate }\end{array}$ & 514 & pounds per acre \\
\hline Total Fertilizer Applied & 226,286 & pounds \\
\hline Total Fertilizer Applied & 113.14 & tons \\
\hline Total Fertilizer Savings & 11.31 & tons \\
\hline Total Fertilizer Savings & $\$ 1,426$ & per year \\
\hline Cost of Sensor & 8300 & per unit \\
\hline Simple Payback & 5.82 & years \\
\hline Return on Investment & $17.2 \%$ & \\
\hline
\end{tabular}



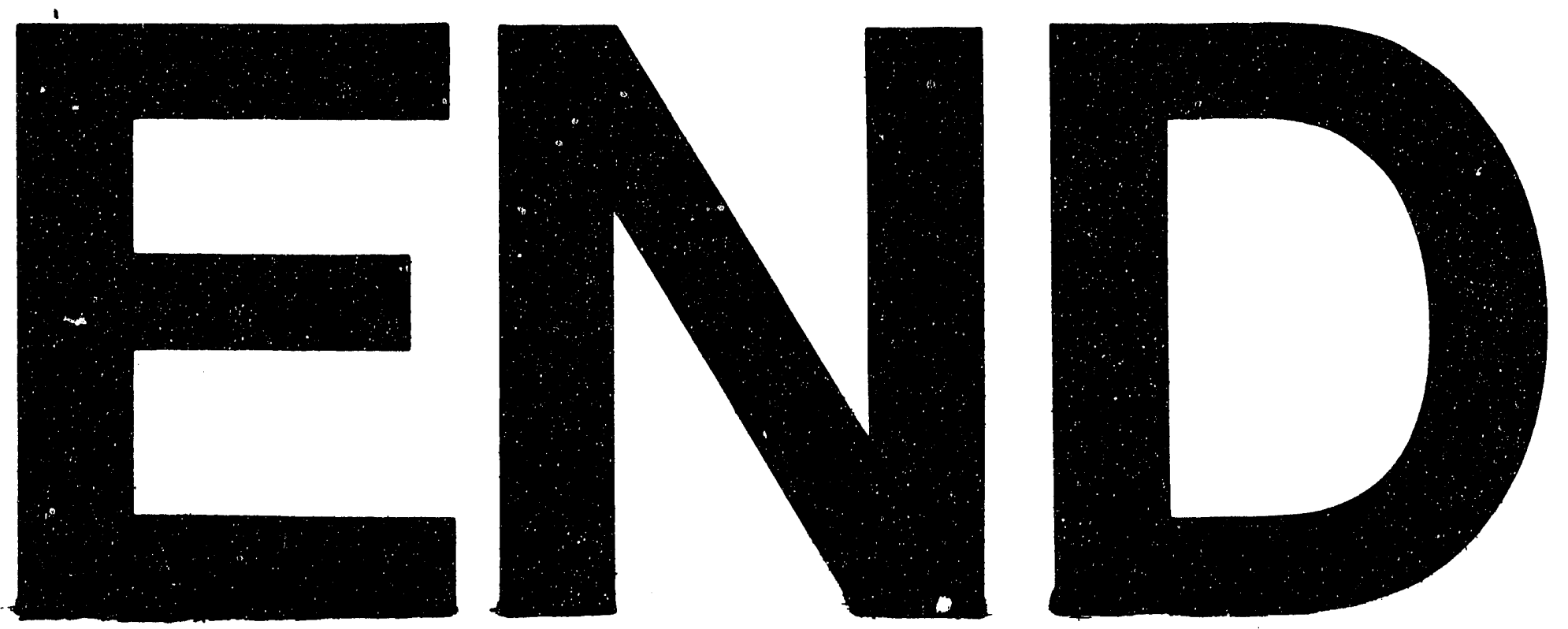

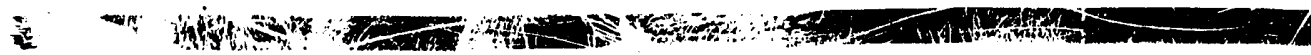

Dh

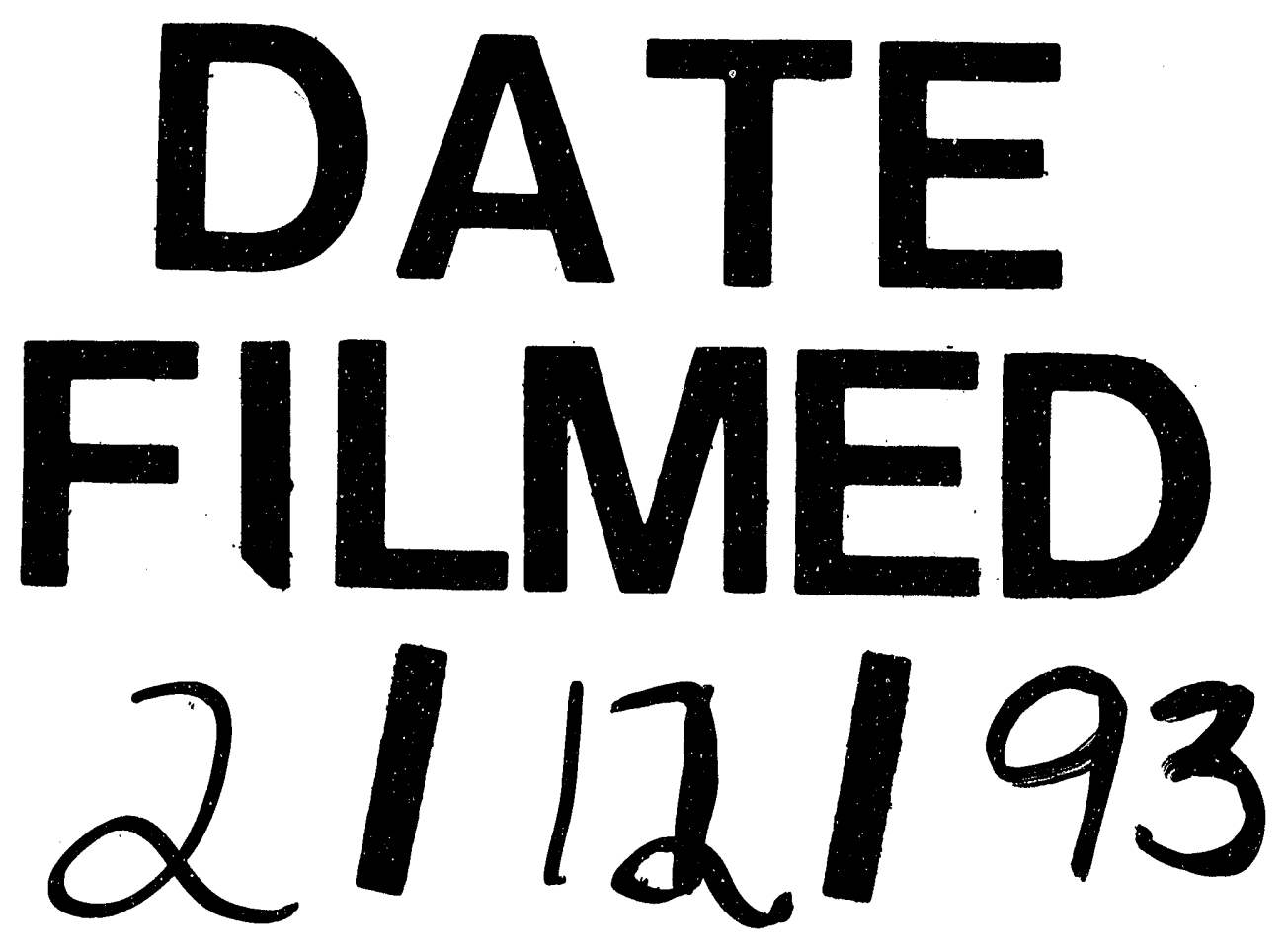




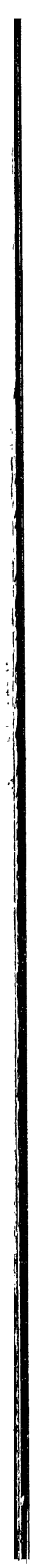

